Article

\title{
Tumour Necrosis Receptor Superfamily Interact with the Mitochondrial Dynamics in Adipose Tissue in Obese Patients without Type 2 Diabetes
}

\author{
Daria Shunkina (Skuratovskaia) ${ }^{1, *}$, Alexandra Komar ${ }^{1}$, Maria Vulf ${ }^{1}$, Hung Vu Quang ${ }^{2}$, Egor Shunkin ${ }^{1}$, Elena \\ Kirienkova ${ }^{1}$, Anastasiia Dakchnevich ${ }^{1}$, Danil Malkov ${ }^{1}$, Pavel Zatolokin ${ }^{1}$ and Larisa Litvinova ${ }^{1}$ \\ 1 Center for Immunology and Cellular Biotechnology, Immanuel Kant Baltic Federal University, Kaliningrad, \\ Russian Federation; post@kantiana.ru \\ 2108 Military Central Hospital, Ha Noi. Vietnam; newsdesk@vnsmail.com \\ * Correspondence: Daria Shunkina DariaSK@list.ru; Tel.: +7 (4012) 59-55-95 (6634)
}

\begin{abstract}
Interactions between receptors and ligands of the tumor necrosis factor superfamily (TNFSF) provide costimulatory signals that control the survival, proliferation, differentiation, and effector function of immune cells. All components of the TNF superfamily are associated with NF$\mathrm{kB}$ functions that are not limited to cell death and may promote survival in the face of adipose tissue inflammation in obesity. Inflammation and pro-inflammatory dysfunction of mitochondria are key factors associated with insulin resistance in obesity. The aim of the study was to analyze the relationship of soluble forms of receptors and ligands of the TNF superfam-ily in blood plasma with mitochondrial dynamics in adipose tissue (greater omentum (GO) and subcutaneous adipose tissue (Sat)) of obese patients with and without type 2 diabetes mellitus (T2DM). Increased plasma sTNFR1, sTNF-R2, sTNFRSF8 receptors and ligands TNFSF12, TNFSF13, TNFSF13B are characteristic of obese patients without T2DM. Increases in TNFSF12, TNFSF13B, and sTNF-R1 levels are associated with decreased glucose concentration and decreased BMI in obese patients. The gene expression levels responsible for regulating mitochondrial dynamics were increased in obese patients without T2DM and were unbalanced in patients with obesity and T2DM.
\end{abstract}

Keywords: NF-kB; non-canonical NF- $\kappa$ B pathway; sTNFR2; sTNFRSF8; sTNFSF13; mitochondrial dynamics; fission and fusion; TFAM

\section{Introduction}

Interactions between ligands of the tumor necrosis factor superfamily (TNFSF) and tumor necrosis factor receptor superfamily (TNFRSF) provide costimulation signals that control the survival, proliferation, differentiation, and effector function of immune cells [1]. Receptors and ligands can be classified into three groups. The first class is death receptors (DR), which contain the death domain (DD). The second class is receptors that interact with members of the TRAF family (TNFR-associated factor). The third class consists of decoy receptors (DcR) without intracellular interacting partners that act as inhibitors of the TNFSF ligand [1].

TNFR1 belongs to the receptor's first class and is expressed in various types of cells [1]. TNFR1 is a DR and contains a death domain DD. TNFR1 is activated by cytotoxicity signaling pathways and promotes an acute inflammatory response. TNFR1 activation induces apoptosis or necroptosis and activates nuclear factor- $\kappa \mathrm{B}(\mathrm{NF}-\kappa \mathrm{B})$ [1].

TNFR2 belongs to the second class of receptors and does not contain a death domain, and does not cause cell death. TNFR2 stimulates the signaling of the non-canonical NF$\kappa B$ pathway. Circulating sTNFR2 has been shown to increase in response to TNF and is negatively associated with insulin sensitivity in obese patients [2]. 
Another receptor of this class, TNFRSF8 (CD30), is forming an immune response, TNF production, and NF- $\kappa$ B activation [3]. TNFRSF8 can promote cell proliferation and survival or suppress replication and lead to apoptosis, depending on other signals and factors [1]. CD30 has many functions that depend on both the microenvironment and target cells.

The second class of receptors has several ligands, TNFSF12 (or tumor necrosis factorlike weak inducer of apoptosis (TWEAK)). TNFSF12 is expressed by leukocytes and is degraded to a soluble form in response to inflammatory stimuli [4]. TNFSF12 activates the NF- $\kappa \mathrm{B}, \mathrm{ERK} 1 / 2$ and p38 pathways and regulates proliferation, migration, differentiation, apoptosis, angiogenesis, and inflammation [4]. The role of TNFSF12 in adipose tissue (AT) and obesity is controversial. The competitive interference ability of sTNFSF12 in TNF $\alpha$ signaling in adipocytes was revealed - sTNFSF12 acted as a protective element in type 2 diabetes mellitus (T2DM) [4].

A proliferation-inducing ligand (APRIL/TNFSF13) and B-cell activating factor (BAFF/TNFSF13B) are associated with B-cell survival and differentiation [5]. TNFSF13 and TNFSF13B bind to two receptors expressed at different stages of B-cell development, a transmembrane activator and calcium modulator, as well as interacting with cyclophilin ligand (TACI) and B-cell maturation protein (BCMA) [5]. TNFRSF13B at 17p12 was identified as a gene influencing the pleiotropy of metabolic syndrome [6]. According to the study, TNFRSF13B can affect cell adhesion and differentiation of adipocytes, insulin/glucose sensitivity, cytokine efficiency, plasma lipid levels, and lipoprotein density [6].

All of the above receptors and ligands of the TNF superfamily are associated with NF-kB, activated in two ways - canonical and non-canonical [7]. The canonical NF- $\kappa B$ pathway is activated mainly due to proinflammatory receptors and genotoxic agents [8]. The non-canonical activation of NF- $\mathrm{B}$ is stimulated by family members of specific TNF receptors belonging to the second and third classes [8].

Mitochondria are key organelles that control the physiological role of adipocytes: differentiation, lipid homeostasis, insulin sensitivity, oxidative capacity, adaptive thermogenesis, and browning of white AT. Interestingly, subcutaneous adipose tissue (SAT) and VAT have several differences [9].

Mitochondrial function is suppressed in obesity [10]. In conditions of excess of free fatty acids into the cell in obesity, mitochondria try to compensate for this, but the reserves are depleted over time [9]. In mitochondria, changes in the electron transport chain (ETC) and membrane potential were found, which led to a change in the permeability of the mitochondrial membrane and reduced the synthesis of ATP [11]. Mitochondria are highly plastic and participate in dynamic processes such as mitochondrial fusion and division. To date, it is completely unknown why mitochondria fission and fusion, but researchers believe that during this process mitochondrial DNA (mtDNA) is exchanged [9]. In addition, mitochondria regulate fusion and fission based on the amount of nutrients to effectively meet the needs of the cell. The fission and fusion processes are referred to as mitochondrial dynamics. The balance between mitochondrial fission and fusion is the central mechanism of bioenergetic adaptation to the metabolic needs of the cell.

The process of mitochondrial fusion is regulated by the proteins GTPases, mitofusin 1 and $2(\mathrm{MFN} 1 / 2)$, and the product of the OPA1 gene, which are located on the outer and inner membranes mitochondria, respectively [9]. Once close contact is established between mitochondria, the fusion of the outer mitochondrial membranes occurs by forming a complex between MFN1 and MFN2. It has been reported that decreased MFN2 expression is associated with decreased mitochondrial function in subcutaneous and visceral VT in obese patients [9]. The mitochondrial fusion process maintains genetic and biochemical homogeneity, allowing for regulating elevated levels of reactive oxygen species (ROS) and mutated DNA.

Mitochondrial dynamics are essential for maintaining a healthy mitochondrial population within the cell. It was found that high glucose content can activate FIS1, which leads to increased fragmentation of mitochondria and overproduction of ROS [11]. 
Thus, it is assumed that the processes of mitochondrial fusion are induced under conditions of optimization of mitochondrial bioenergetics. In contrast, the processes of division are associated with the degradation of mitochondria (damage to mitochondria). Successful control of these processes can provide several therapeutic approaches, one of which is the modulation of processes associated with mitochondria: mitochondrial dynamics, apoptosis, and autophagy.

All of the above indicates the relationship between the superfamily TNF and NF- $\kappa \mathrm{B}$ signaling with mitochondrial biogenesis [12,13]. A deeper understanding of the relationship between NF- $\kappa \mathrm{B}$ and mitochondrial dynamics is an important area of research for regulating genes and pathways that are activated in chronic inflammation.

Thus, the study aimed to analyze the relationship of soluble forms of receptors and ligands of the TNF superfamily in blood plasma with mitochondrial dynamics in adipose tissue (greater omentum (GO) and subcutaneous adipose tissue (Sat)) of obese patients with and without T2DM.

\section{Materials and Methods}

\subsection{Serum/plasma blood studying}

33 conditionally healthy donors $\left(B M I=22.5 \pm 2.5 \mathrm{~kg} / \mathrm{m}^{2}, 39 \pm 8\right.$ years, 11 men and 22 women), 118 obese patients without T2DM $\left(41.8 \pm 7.0 \mathrm{~kg} / \mathrm{m}^{2}, 42 \pm 10\right.$ years, 30 men and 88 women) and 196 obese patients with T2DM $\left(45.1 \pm 8.7 \mathrm{~kg} / \mathrm{m}^{2}, 45 \pm 9\right.$ years, 41 men 155 women) were studied.

Samples of biological material (biopsies of AT of different localization) from obese patients were taken during different types of bariatric surgery according to indications: gastric bypass or longitudinal resection. Tissue biopsies were taken from healthy donors during routine laparoscopic operations: inguinal and femoral hernias (right or left), diaphragmatic and ventral hernias, nephroptosis.

The presence of obesity and T2DM was established on the basis of a detailed clinical and instrumental examination in a specialized hospital, guided by the World Health Organization (1999-2013) criteria for diagnosing diabetes and other types of hyperglycemia [14]. Informed consent was signed by all patients. Verification of the diagnosis and recruitment of patients into the study groups was carried out at the Department of Reconstructive and Plastic Surgery on the basis of regional clinical hospital in Kaliningrad.

The study was conducted according to the guidelines of the Declaration of Helsinki, and approved by the Institutional Review Board (or Ethics Committee) of IKBFU (protocol code 2 and 29.11.2018).

The analysis of biochemical parameters in blood serum (Glucose, Cholesterol, highdensity lipoproteins (HDL), low-density lipoproteins (LDL), and triglycerides) was carried out on an automatic biochemical analyzer Furuno CA-180 (Furuno Electric Company, Japan) using DiaSys test systems (DiaSys Diagnostic Systems, Germany).

Flow fluorimetry was used to assess the content of cytokines (sTNF-R1, sTNF-R2, sCD30/TNFRSF8, TWEAK/TNFSF12, APRIL/TNFSF13, BAFF/TNFSF13B and IL-10) in blood plasma using the Bio-Plex Pro ${ }^{\mathrm{TM}}$ Human Inflammation Panel 1, 37-Plex \#171al001m (Bio-Rad, USA) on a two-beam laser automated analyzer (BioPlex ${ }^{\circledR} 200$ Systems, Bio-Rad, USA) and BioPlexManager software (Bio-Rad, USA).

The concentration of the TNF- $\alpha$ molecule in the blood plasma was measured using the ELISA method (Vector-Best kits, Russia) on a Lasurit automatic enzyme-linked immunosorbent analyzer (Dynex Technologies, USA).

\subsection{Gene expression research}

Total RNA from homogenized biopsies of AT was isolated using an ExtractRNA kit (Evrogen, Russia). The resulting RNA was dissolved in $30 \mu \mathrm{L}$ of Nuclease-Free Water. The purity and concentration of the isolated RNA were determined using a spectrophotometer 
(Nanovue Plus, GE Healthcare Bio-Sciences, Sweden). The quality of total RNA was determined by the RIN index (the RNA Integrity Number). The reverse transcription procedure was performed using (dT) 23 (Beagle, Russia) and M-MLV reverse transcription (Evrogen, Russia). To determine relative gene expression levels, qPCR was performed using qPCRmix-HS reagents (Evrogen, Russia). As a template, we used $4 \mu \mathrm{L}$ of cDNA, as a reference gene-RPLPO (a large ribosomal protein).

Table 1. Sequences of primers and probes for PCR.

\begin{tabular}{|c|c|}
\hline Gene name & Sequences of primers and probes \\
\hline \multirow{3}{*}{ RPLPO } & F: 5'-GGCGACCTGGAAGTCCAACT-3' \\
\hline & R: 5'-CCATCAGCACCACAGCCTTC-3' \\
\hline & Bgl635-5'-ATCTGCTGCATCTGCTTGGAGCCCA-3'-BHQ-2 \\
\hline \multirow{3}{*}{ NFkB1 } & F: 5'-CAGGAAGATGTGGTGGAGGA-3' \\
\hline & R: 5'- TGGGGTGGTCAAGAAGTAGTG-3' \\
\hline & FAM-5'-CCTTCTGGACCGCTTGGGTAACTCTGT-3'-BHQ-1 \\
\hline \multirow{3}{*}{ TFAM } & F: 5'-CGCTCCCCCTTCAGTTTTGT-3' \\
\hline & R: 5'-TACCTGCCACTCCGCCCTAT-3' \\
\hline & FAM-5'-CGAGGTGGTTTTCATCTGTCTTGGCA-3'-BHQ-1 \\
\hline \multirow{3}{*}{ DNM1L } & F: 5'-TCTGGAGGTGGTGGGGTTG-3' \\
\hline & 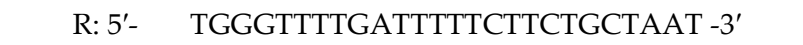 \\
\hline & FAM-5'-ACCAACCACAGGCAACTGGAGAGGA-3'-BHQ-1 \\
\hline \multirow{3}{*}{ MFN2 } & F: 5'-CCAGCGTCCCATCCСTCT-3' \\
\hline & R: 5'-TCCACACСАСТССТССАACA-3' \\
\hline & FAM-5'-ACAGGGCTCGCTCACCCAGGAG-3'-BHQ-1 \\
\hline
\end{tabular}

\subsection{Western blotting analysis}

Protein lysates were obtained using RIPA buffer $(n=8)$ (BioRad, USA) and normalized by the Bradford method (reagent Bradford BioRad buffer, USA) with separation by polyacrylamide gel electrophoresis (BioRad, USA). Tansfer of proteins was carried out on a PVDF membrane at $+4 \mathrm{C}$ for $2 \mathrm{~h}$ (BioRad, USA). Hybridization of the target proteins was carried out with the corresponding primary antibodies and secondary antibodies labeled with horseradish peroxidase (Thermo Fisher Scientific, USA) using a substrate for visualization of Western blots ECL Plus (Thermo Fisher Scientific, USA). The analysis of the staining intensity of the bands was carried out in the Image J program with normalizations for the GAPDH protein.

Incubation with primary antibodies was performed overnight at +4 . Incubation with secondary antibodies conjugated with horseradish peroxidase (Thermo Fisher Scientific, USA) was carried out for $2 \mathrm{~h}$. Next, densitometry was measured on a ChemiDoc MP (BioRad, USA) using a substrate for visualizing Western blots ECL Plus (Thermo Fisher Scientific, USA). The following primary antibodies were used: NFkB (701079, Invitrogen, USA), mitochondrial transcription factor A (TFAM) (MA5-16148, Thermo Fisher Scientific, USA), dynamin-1-like protein (DRP1) (OTI3F4, Invitrogen, USA), mitofusin 2 (MFN2) (MA5-27647, Invitrogen, USA). The all target protein were normalizations the glyceraldehyde 3-phosphate dehydrogenase (GAPDH) protein (ZG003, Thermo Fisher Scientific, USA).

\subsection{Statistical analysis}

The normal distribution of quantitative indicators was checked using the Kolmogorov-Smirnov test and the Shapiro-Wilk test. With a normal distribution, the hypothesis of equality of the mean sample values was tested using the Student $t$-test. The nonparametric Kruskal-Wallace test applied the significance of differences between independent quantitative samples not having a normal distribution law. In case of statistically significant differences between the groups, analysis was performed using the Mann-Whitney test. Differences were considered significant at a significance level of $\mathrm{p}<$ 0.05 . 
To determine relative gene expression levels, qPCR was performed using qPCRmixHS reagents (Evrogen, Russia). As a template, we used $4 \mu \mathrm{L}$ of cDNA, as a reference gene-RPLPO (a large ribosomal protein). Gene expression levels were calculated using the delta-delta $\mathrm{Ct}$ method, also known as $2-\Delta \mathrm{Ct}$. The formula was used to calculate the relative frequency of gene expression in the samples [15].

The analysis of the band staining intensity was carried out using the Image Lab Software (Bio-Rad, USA) with normalizations for the glyceraldehyde 3-phosphate dehydrogenase (GAPDH) protein (ZG003, Thermo Fisher Scientific, USA).

The presence of a relationship between the studied parameters was carried out using Spearman correlation. Correlations were calculated in each group and for all patients (general correlations). For the analysis of an adequate linear regression model, the following regression residues were considered: the lack of autocorrelation of residues (Durbin-Watson test, $\mathrm{p}$-values $>0.05$ ) and its normal distribution and the consistency of the dispersion residues (heteroscedasticity test, $\mathrm{p}$-values $<0.05$ were considered significant). Multi linear regression Least squares gaussian distribution of residuals was visualized using GraphPad Prism 9.00. Statistical analyzes and graphs were generated in GraphPad Prism 8.01 from the output data.

\section{Results}

\subsection{Biochemical parameters of obese patients}

The results of blood biochemical parameters are presented in Figure 1. Lipid metabolism disorders were detected in obese patients with T2DM. In this category of patients, the levels of cholesterol, high-density lipoproteins (HDL), low-density lipoproteins (LDL), and triglycerides were outside the reference values. The cholesterol level in all patients was higher than in the control group $(\mathrm{p}<0.05)$. The cholesterol in obese patients with T2DM exceeded the values of patients without T2DM (Figure 1) $(\mathrm{p}<0.05)$. The triglycerides and LDL in serum in all obese patients were higher than in control group. The triglycerides level reached maximum values in the group of patients with T2DM (Figure 1) $(\mathrm{p}<0.05)$. 


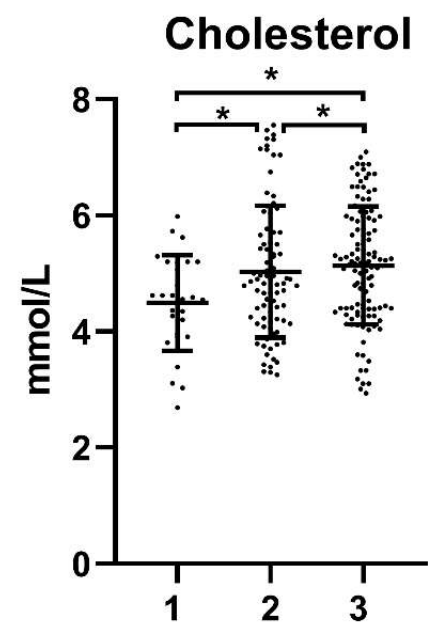

HDL

Glucose
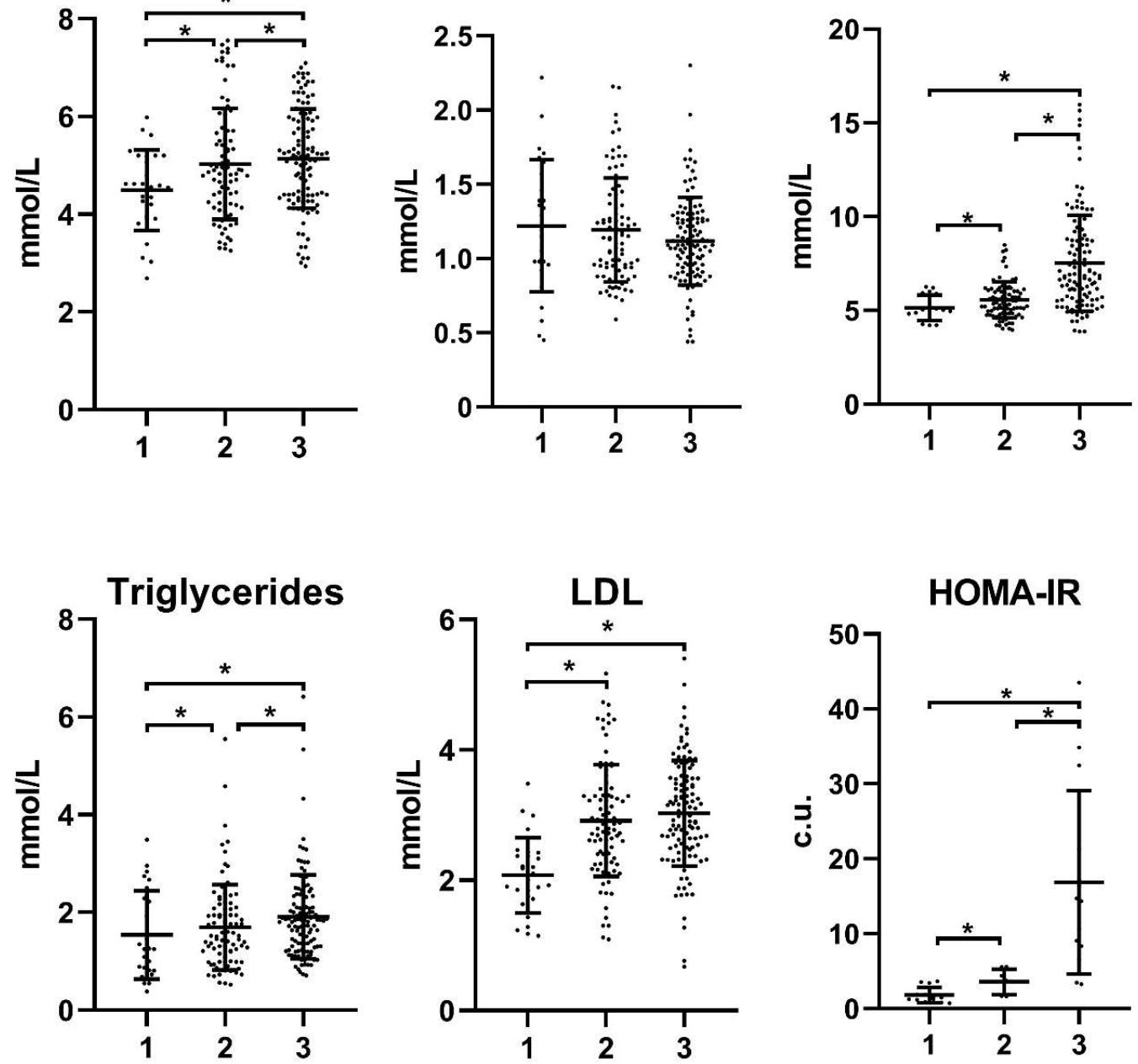

Figure 1. Biochemical parameters of carbohydrate and lipid metabolism in obese patients with and without T2DM. ${ }^{*}-\mathrm{p}<$ 0.05 the significance is determined using the Mann-Whitney criterion for two independent samples.

\subsection{The concentration of plasma cytokines of the TNF receptor superfamily in obese patients}

The concentration of plasma cytokines of the TNF receptor superfamily (receptors sTNF-R1, sTNFRSF8, and ligands - TNFSF12, TNFSF13, TNFSF13B) in obese patients with T2DM was lower than in patients without T2DM and control group $(\mathrm{p}<0.05)$ (Table 1). The levels of receptors sTNF-R1, sTNF-R2, sTNFRSF8, and ligands TNFSF12, TNFSF13, TNFSF13B in obese patients without T2DM were higher in comparison with the group of patients with T2DM and control group $(\mathrm{p}<0.05)$ (Table 2$)$. 
Table 2. The level of pro- and anti-inflammatory cytokines in patients with and without T2DM.

\begin{tabular}{|c|c|c|c|}
\hline Cytokine (pg/ml) & Control group & $\begin{array}{c}\text { Obese patients without } \\
\text { T2DM } \\
\end{array}$ & $\begin{array}{c}\text { Obese patients with } \\
\text { T2DM } \\
\end{array}$ \\
\hline TNF-a & $2.120(1.56-3.120)$ & $\begin{array}{c}14.71(10.44-16.89) \\
\mathrm{p}_{1-2<0.001^{*}}\end{array}$ & $\begin{array}{c}32.86(20.15-34.42) \\
\text { p}_{1-3}<0.001^{*} \\
\text { p2-3 }^{*}<0.001^{*}\end{array}$ \\
\hline sTNF-R1 & $110,36(89,41-229,08)$ & $\begin{array}{c}591,57(187,88-1229,37) \\
\mathrm{p}_{1-2<0,001^{*}}\end{array}$ & $\begin{array}{c}96,1(53,05-134,83) \\
\mathrm{p}_{1-3}=0,021^{*} \\
\mathrm{p}_{2-3}<0,001^{*}\end{array}$ \\
\hline sTNF-R2 & $59,39(48,03-111,73)$ & 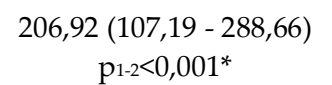 & $\begin{array}{c}86,10(52,21-137,23) \\
\text { p2-3< }^{2}<001^{*}\end{array}$ \\
\hline sTNFRSF8 & $\begin{array}{c}31,82 \\
(22,61-50,17)\end{array}$ & $\begin{array}{c}65,13(34,26-116,48) \\
\text { p1-2<0,001* }\end{array}$ & $\begin{array}{c}23,01(14,51-35,53) \\
\text { p1-3=0,023* } \\
\text { p2-3<0,001* }\end{array}$ \\
\hline TNFSF12 & $347.33(247.81-464.02)$ & $\begin{array}{c}541.25(278.36-691.23) \\
\mathrm{p}_{1-2}=0.050^{*}\end{array}$ & 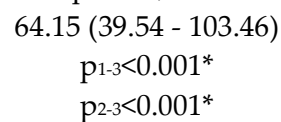 \\
\hline TNFSF13 & $\begin{array}{c}20872.63(17224.93- \\
31761.95)\end{array}$ & $\begin{array}{c}48896.8(28910.78- \\
80400.51) \\
\text { p1-2<0.001* }\end{array}$ & $\begin{array}{c}14131.77(8361.43- \\
20974.42) \\
\text { p1-3 }=0.001^{*} \\
\text { p2-3<0.001* }\end{array}$ \\
\hline TNFSF13B & $\begin{array}{c}2103.81(1565.48- \\
3381.11)\end{array}$ & $\begin{array}{c}3411.06(2610.11- \\
5571.37) \\
\text { p1-2<0.001* }\end{array}$ & $\begin{array}{c}1387.88(921.86- \\
2135.25) \\
\text { p1-3 }=0.001^{*} \\
\text { p2-3<0.001* }\end{array}$ \\
\hline IL-10 & $0.64(0.32-1.53)$ & $\begin{array}{c}2.18(1.11-3.44) \\
\text { p1-2=0.001* }\end{array}$ & $\begin{array}{c}0.75(0.26-0.99) \\
\text { p2-3<0.001* }\end{array}$ \\
\hline
\end{tabular}

Note: the significance is determined using the Mann-Whitney criterion for two independent samples $\left({ }^{*}-\mathrm{p}<0.05\right)$.

Plasma levels of receptors and TNF ligand decreased with increasing BMI. A negative relationship was found between the levels of sTNF-R1, sTNF-R2, sTNFRSF8, TNFSF12, TNFSF13, TNFSF13B with BMI $(r=-0.426 ; \mathrm{r}=-0.413 ; \mathrm{r}=-0.321 ; \mathrm{r}=-0.417 ; \mathrm{r}=$ $0.517 ; \mathrm{r}=-0.405$ ) (Figure 2).

The levels of sTNF-R1, sTNF-R2, sTNFRSF8, TNFSF12, TNFSF13, TNFSF13B was correlated with level of IL-10 $(\mathrm{r}=0.495 ; \mathrm{r}=0.394 ; \mathrm{r}=0.564 ; \mathrm{r}=0.578 ; \mathrm{r}=0.563 ; \mathrm{r}=0.494 ; \mathrm{r}=$ 0.552) general correlations (in all studied patients) $(\mathrm{p}<0.05)$. The sTNF-R1, sTNF-R2, sTNFRSF8, TNFSF13, TNFSF13B levels was negative correlated with TNF-a levels $(\mathrm{r}=-$ $0.521 ; \mathrm{r}=-0.579 ; \mathrm{r}=-0.518 ; \mathrm{r}=-0.478 ; \mathrm{r}=-0.566)(\mathrm{p}<0.05)$ general correlations (in all studied patients) (Figure 2). All studied obese patients showed a positive relationship between the levels of sTNF-R1, TNFSF12, TNFSF13, TNFSF13B with HDL levels $(r=0.264 ; r=0.410 ; r$ $=0.266 ; \mathrm{r}=0.355)$. The levels of sTNF-R1, sTNFRSF8, TNFSF12, TNFSF13, TNFSF13B negative correlated with LDL levels $(\mathrm{r}=-0.278 ; \mathrm{r}=-0.276 ; \mathrm{r}=-0.361 ; \mathrm{r}=-0.295 ; \mathrm{r}=-0.274)$. Plasma levels of sTNFRSF8, TNFSF12, TNFSF13 negatively correlated with glucose levels $(\mathrm{r}=-0.306 ; \mathrm{r}=-0.288 ; \mathrm{r}=-0.300)$ in all obese patients. 


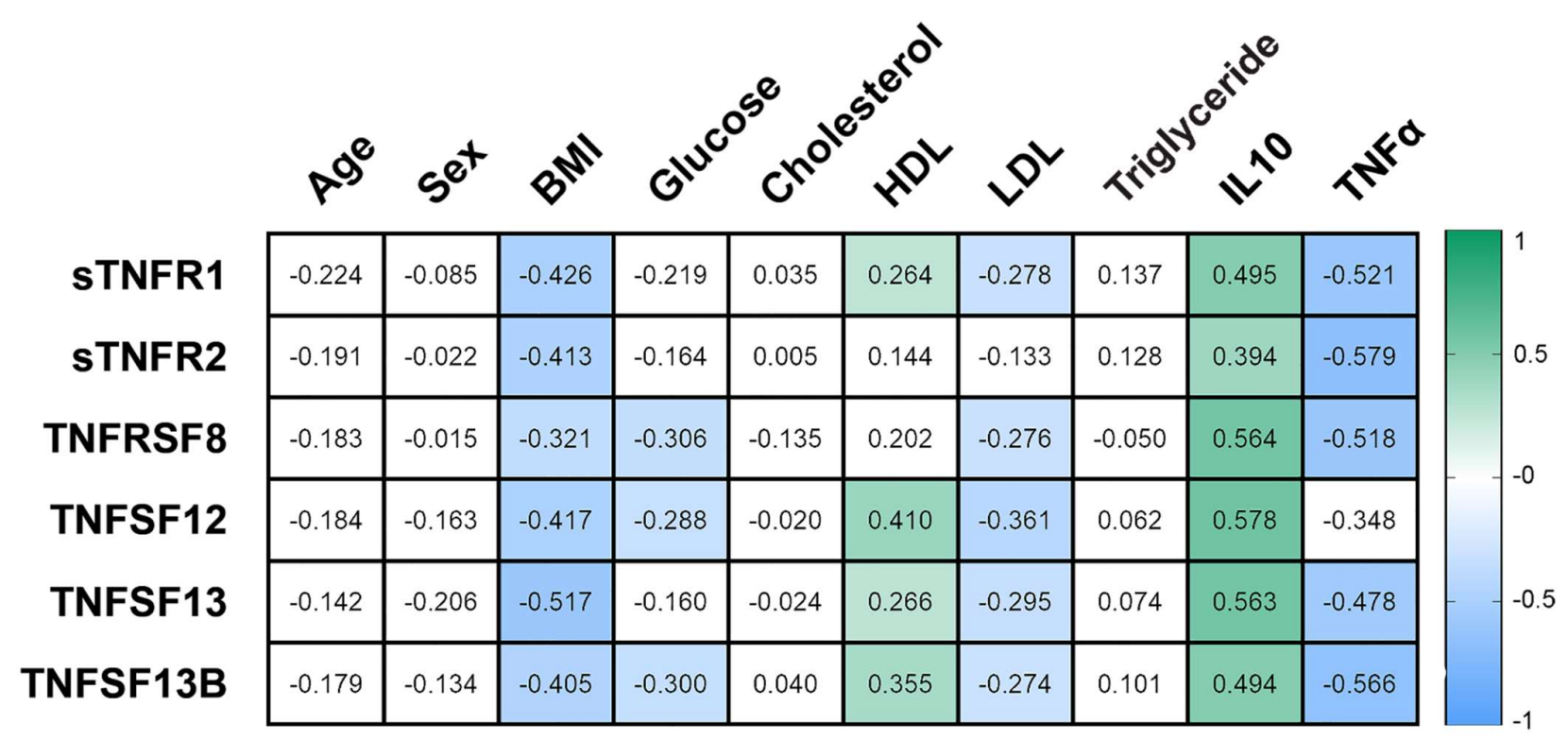

Figure 2. Correlation relationships of sTNF-R1, sTNF-R2, sTNFRSF8, and ligands - TNFSF12, TNFSF13, TNFSF13B with biochemical parameters in all obese patients. Filled squares show significant $\mathrm{p}<0.05$.

sTNF-R1， sTNF-R2， sTNFRSF8，TNFSF12, TNFSF13， TNFSF13B levels were positively correlated with each other in obese patients (Figure 3).

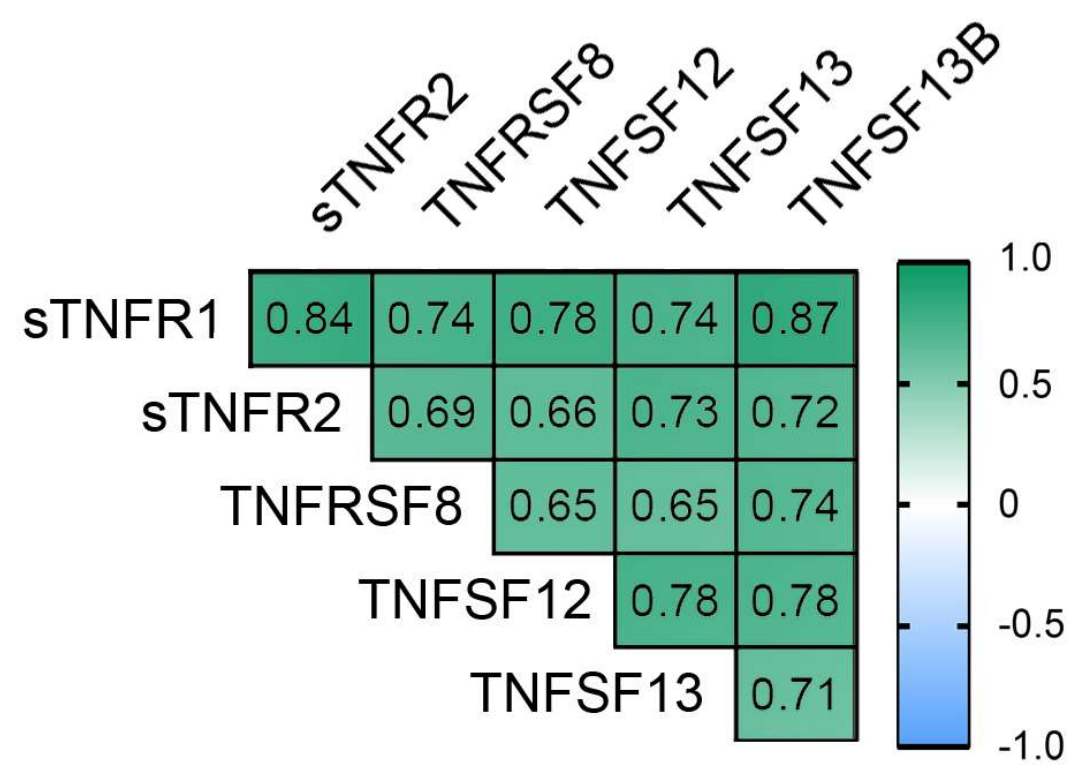

Figure 3. Correlation relationships between sTNF-R1, sTNFRSF8, and ligands - TNFSF12, TNFSF13, TNFSF13B. Filled squares show significant $\mathrm{p}<0.05$.

Regression analysis was carried out to prove that an increase in the level of TNF class 2 receptors and ligands in blood plasma is not accidentally associated with an improvement in the parameters of carbohydrate and lipid metabolism in the serum of obese patients. We analyzed whether receptors affect the biochemical parameters of obese patients (Figure 4) (Table 3). We showed by regression multivariate analysis that an increase in STNF-R1, TNFSF12 and TNFSF13B levels affects a decrease in $\mathrm{BMI}$, and glucose levels in blood plasma. We showed by regression multivariate 
analysis that an increase in TNFSF12 and TNFSF13B levels affects a decrease in blood glucose concentration, a reduction in BMI, and increased IL10 levels in blood plasma.
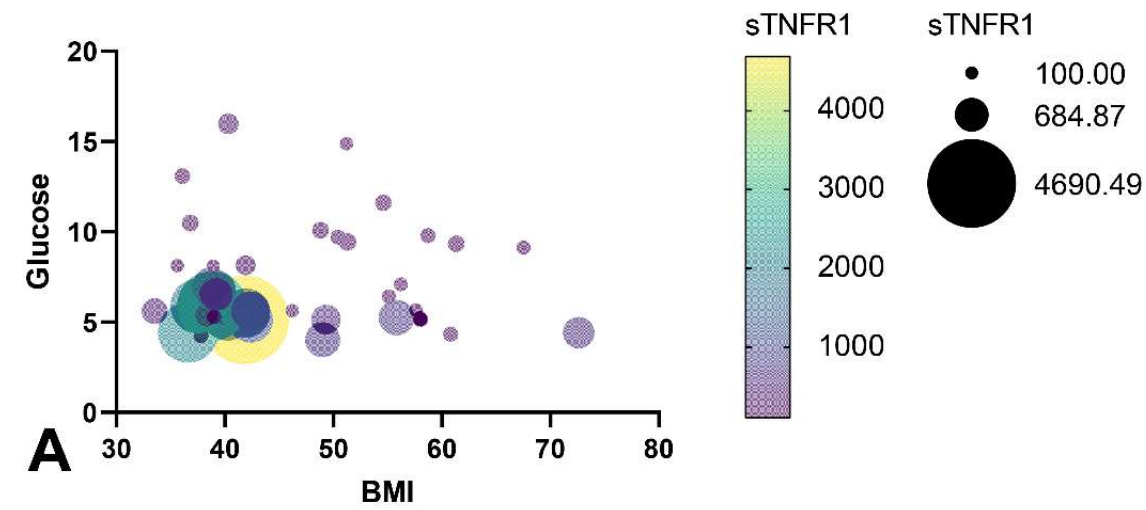

2000

1000
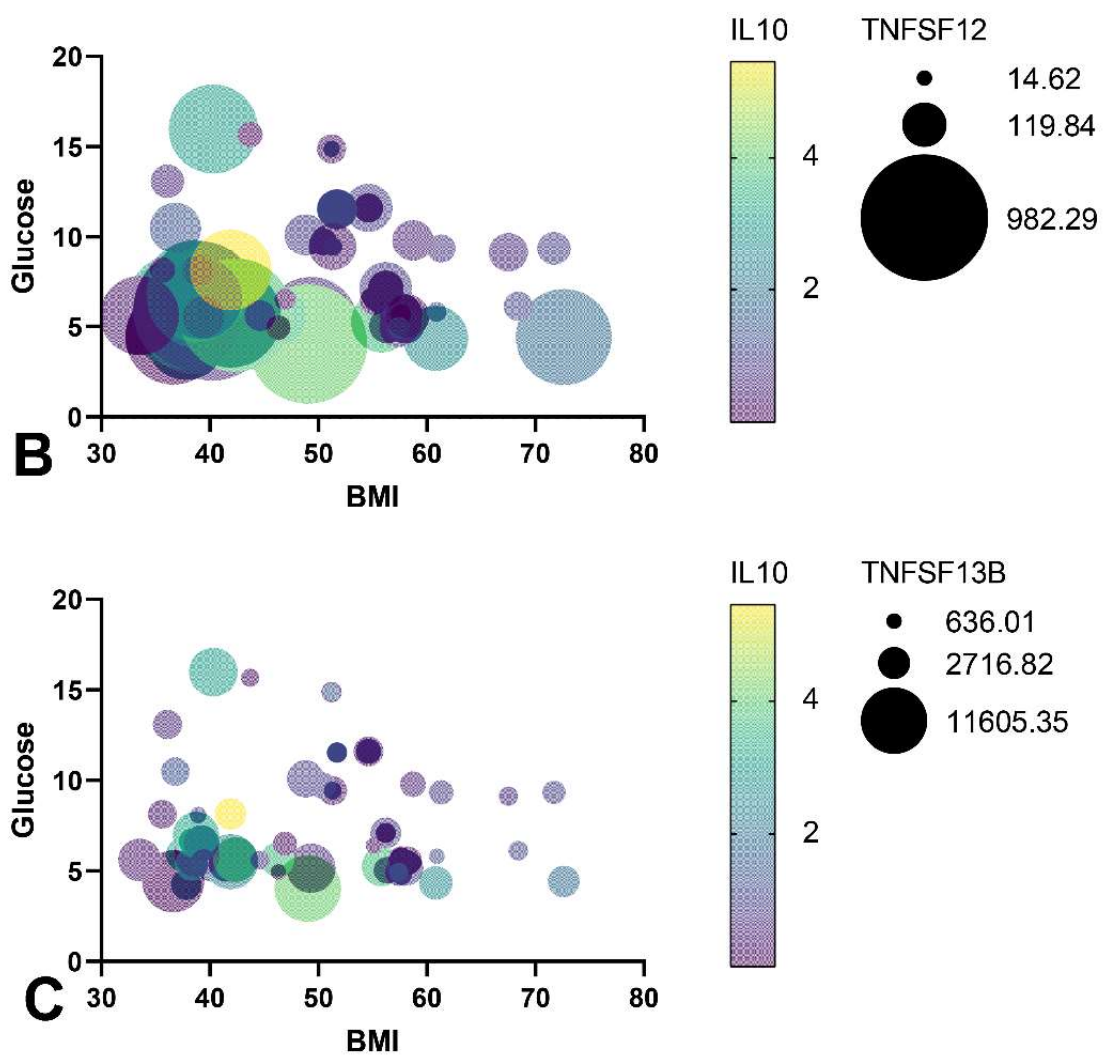

2

Figure 4. Models of multiple regression analysis of the relationship between the sTNF-R1, TNFSF12, TNFSF13B levels and glucose level, IL10 level, BMI (significant $\mathrm{p}<0.05$ ).

Table 3. Models of multiple regression analysis of the relationship between the sTNF-R1. TNFSF12, TNFSF13B levels and glucose level, IL10 level, BMI

\begin{tabular}{c|c|c|c|c|c|c}
\hline Multiple regression & $\begin{array}{c}\text { Dependent } \\
\text { variable }\end{array}$ & $\begin{array}{c}\text { Independen } \\
\mathrm{t} \text { variable }\end{array}$ & $\beta$ & $\begin{array}{c}\text { Standard } \\
\text { error }\end{array}$ & $\mathrm{t}$ value & $\mathrm{p}$-value \\
\hline $\begin{array}{c}\text { Multiple regression linear } \\
\text { Model 1 }\end{array}$ & sTNF-R1 & BMI & -0.297 & 0.105 & -2.819 & $0.0063^{*}$ \\
\hline
\end{tabular}




\begin{tabular}{|c|c|c|c|c|c|c|}
\hline $\begin{array}{c}\text { Multiple R-squared }=0.167, \\
\text { Adjusted R-squared }=0.141, \\
\text { p-value }=0.0026\end{array}$ & & Glucose & -0.241 & 0.110 & -2.179 & 0.0329 * \\
\hline \multirow{3}{*}{$\begin{array}{l}\begin{array}{c}\text { Multiple regression linear } \\
\text { Model } 2\end{array} \\
\text { Multiple R-squared }=0.466, \\
\text { Adjusted R-squared }=0.438, \\
\text { p-value }=7.086 \mathrm{e}-08\end{array}$} & \multirow{3}{*}{ TNFSF12 } & BMI & -0.325 & 0.082 & -3.927 & $0.0002^{*}$ \\
\hline & & Glucose & -0.262 & 0.085 & -3.082 & $0.0031^{*}$ \\
\hline & & IL10 & 0.439 & 0.122 & 3.585 & $0.0006^{*}$ \\
\hline \multirow{3}{*}{$\begin{array}{c}\text { Multiple regression linear } \\
\text { Model } 3 \\
\text { Multiple R-squared }=0.290, \\
\text { Adjusted R-squared }=0.252, \\
\text { p-value }=0.0001\end{array}$} & \multirow{3}{*}{ TNFSF13B } & BMI & -0.251 & 0.093 & -2.693 & $0.0092^{* *}$ \\
\hline & & Glucose & -0.196 & 0.095 & -2.052 & 0.0447 * \\
\hline & & IL10 & 0.341 & 0.137 & 2.479 & 0.0161 * \\
\hline
\end{tabular}

Thus, increases in TNFSF12, TNFSF13B, and sTNF-R1 levels are associated with decreased glucose concentration and decreased BMI in obese patients.

\subsection{The NF-kB levels in obese patients}

$N F-k B 1$ gene expression in GO and in SAT increased in obese patients without T2DM compared with the control group $(\mathrm{p}<0.05)$ (Figure 5A). NF- $k B 1$ gene expression in GO in patients with T2DM was higher than the control group and did not differ in obesity patients without T2DM $(\mathrm{p}<0.05)$. NF-kB1 gene expression in SAT in patients with T2DM was lower than obesity patients without T2DM $(\mathrm{p}<0.05)$. The production of NF-kB $(\operatorname{RelA})$ protein in GO and SAT did not change in obese patients without T2DM compared with the control group $(\mathrm{p}<0.05)$ (Figure 5B, 5C). 

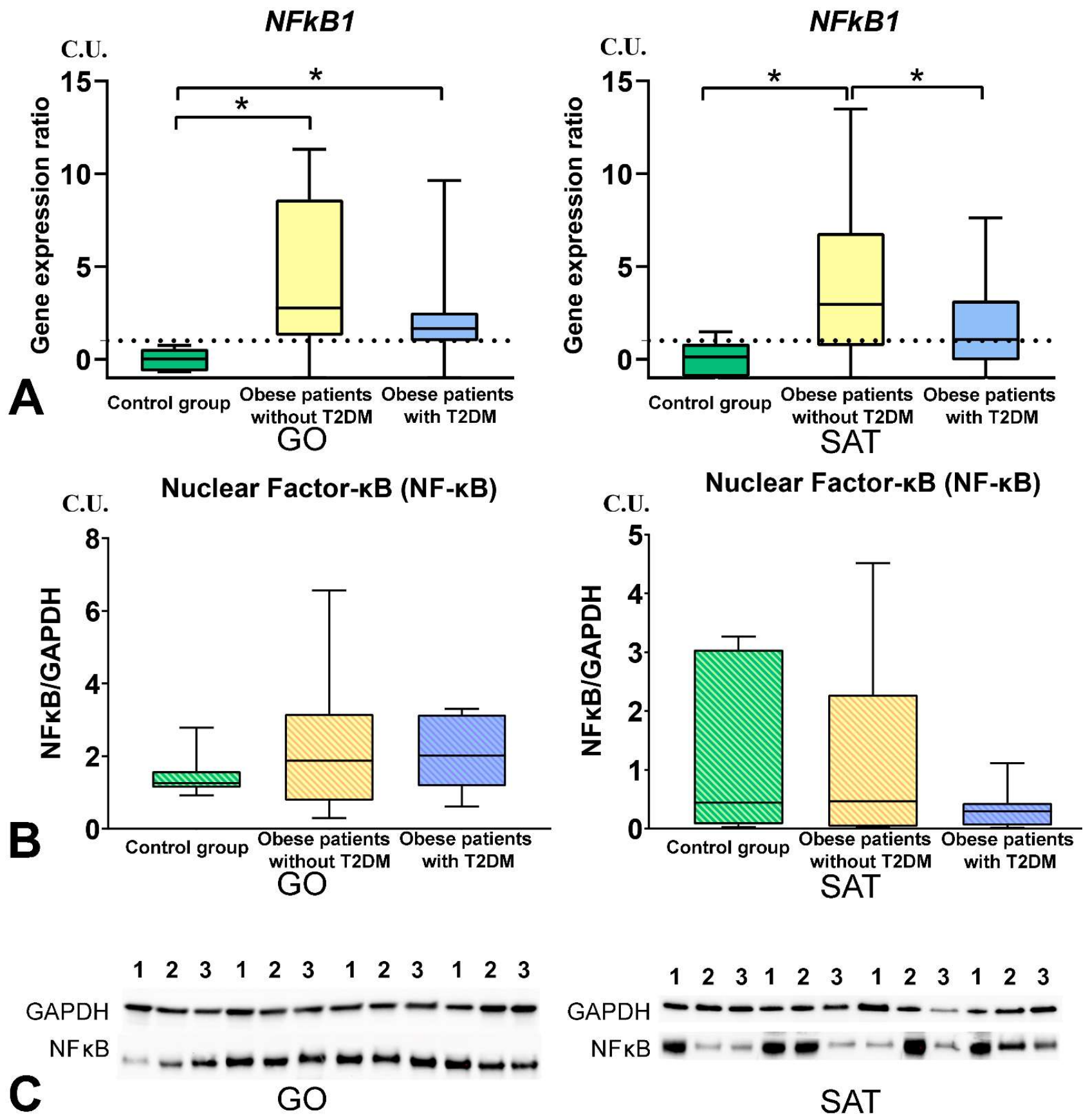

Figure 5. Study of NF-kB tissue-specific production in obese patients with and without T2DM. (a) - NF-kB1 gene expression in GO and SAT; (b) - NF-kB (p65) protein production in GO and SAT, western blot analysis of AT biopsies; (c) - Protein NF-kB (p65) Western Blot Bands. * - p<0.05 the significance is determined using the Mann-Whitney criterion for two independent samples.

\subsection{Mitochondrial Dynamics - Division and Fusion}

DNM1L gene expression in GO and SAT in obese patients without T2DM was higher than in the control group (Figure 6). MFN2 gene expression in GO and SAT in obese patients without T2DM was higher than in the control group (Figure 7). TFAM gene expression in GO and SAT in obese patients without T2DM was higher than in the control group (Figure 8). DNM1L, MFN2, and TFAM gene expression positively correlated with each other in GO. NF- $k B 1, D N M 1 L, M F N 2$, and TFAM gene expression positively correlated with each other in SAT (Figure 9). 
Dinamin-1-like protein production in SAT in obese patients with T2DM was higher than in obese patients without T2DM (Figure 6). Transcription factor A protein production in SAT in obese patients with T2DM was lower than in the control group (Figure 5).

Thus, an increase in the activity of genes for mitochondrial dynamics is characteristic of obese patients without T2DM. In obese patients with T2DM, the production of Dinamin-1-like protein was increased, on the contrary, the output of the Transcription factor A protein was decreased in comparison with other patient groups.

DNM1L
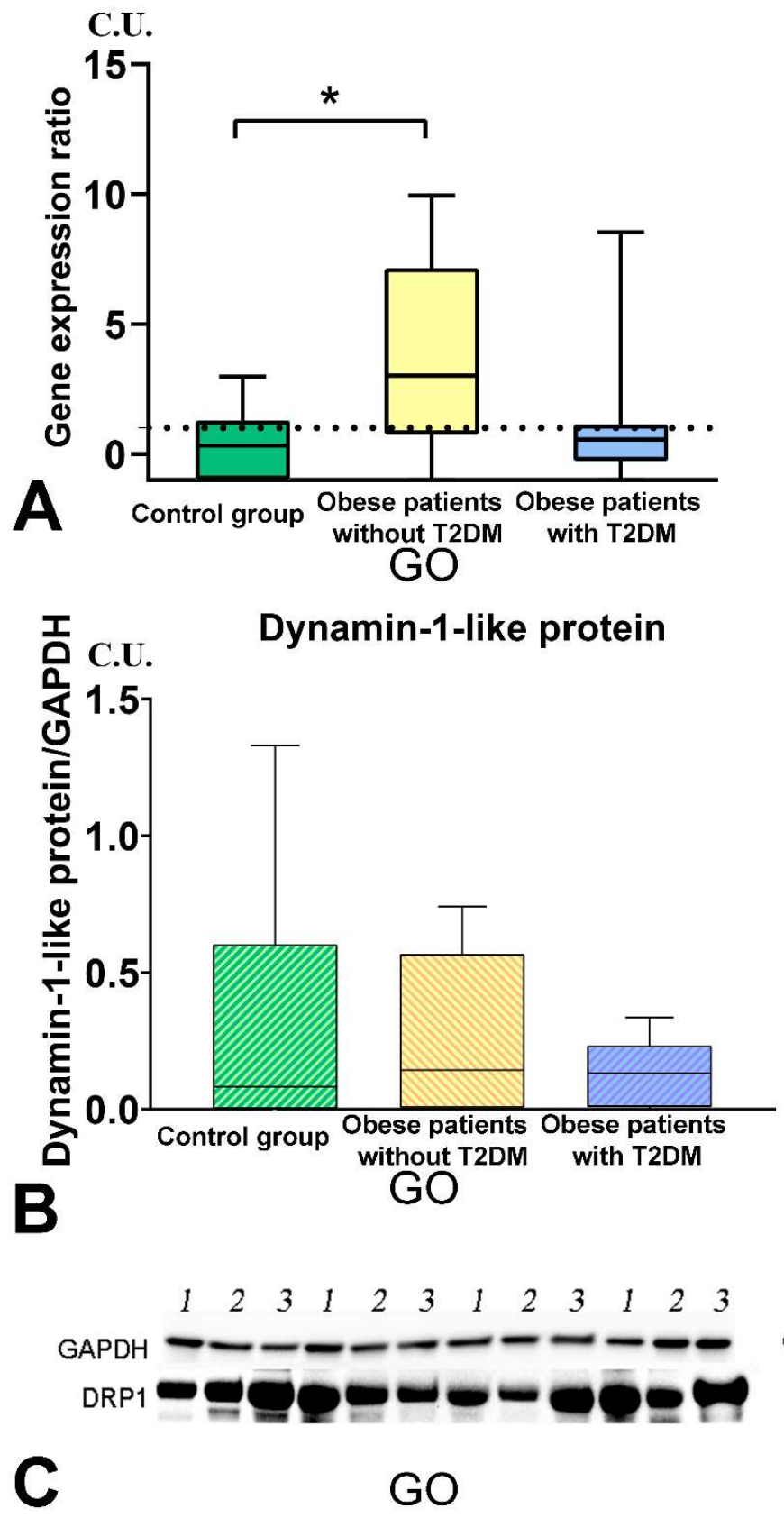

\section{DNM1L}
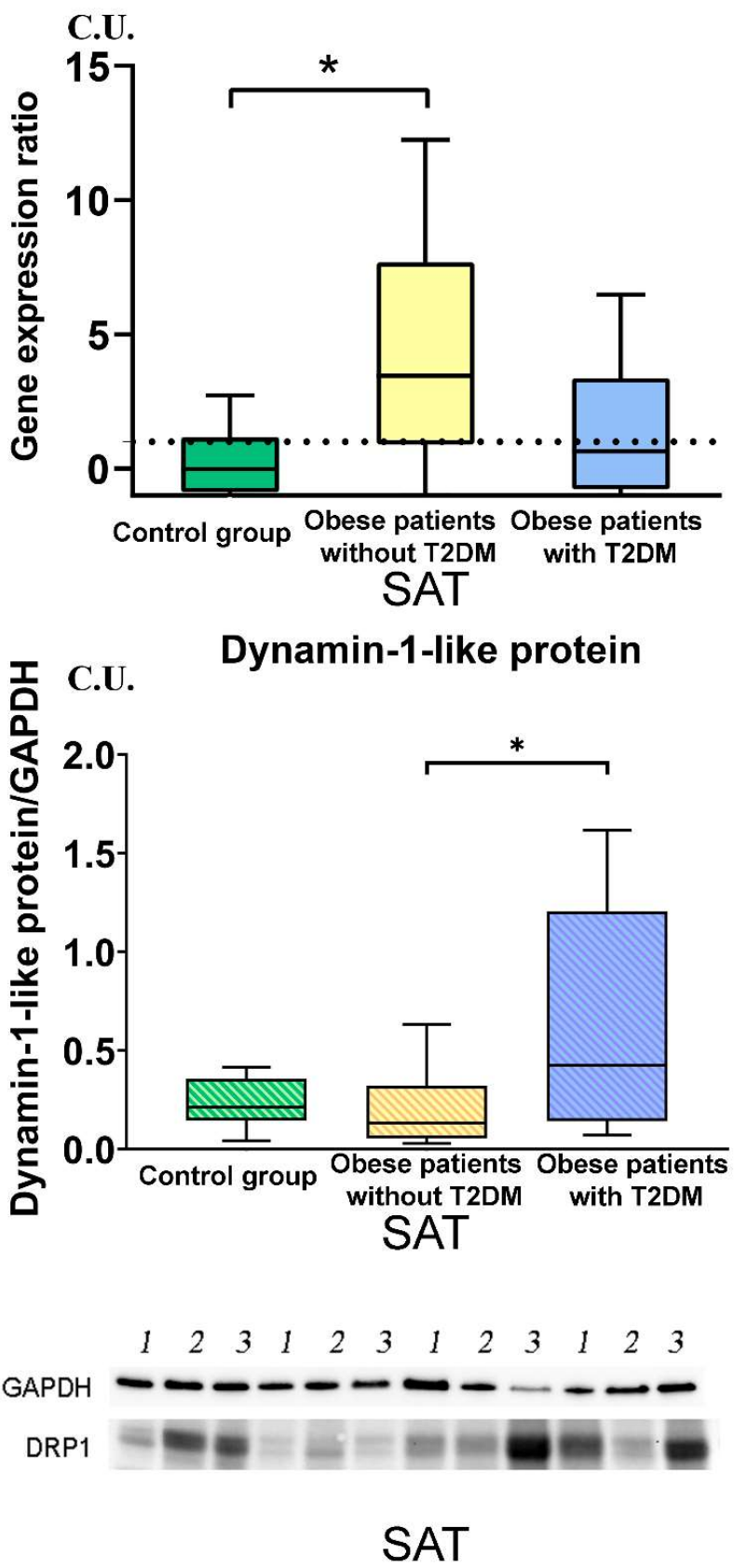

Figure 6. Study of tissue-specific production of DNM1L in obese patients with and without T2DM. (a) - DNM1L genes expression in GO and SAT; (b) - Dynamin-1-like protein (DRP1) production in GO and SAT, western blot analysis of AT biopsies; (c) - Protein DRP1 Western Blot Bands. * - $\mathrm{p}<0.05$ the significance is determined using the Mann-Whitney criterion for two independent samples. 
MFN2

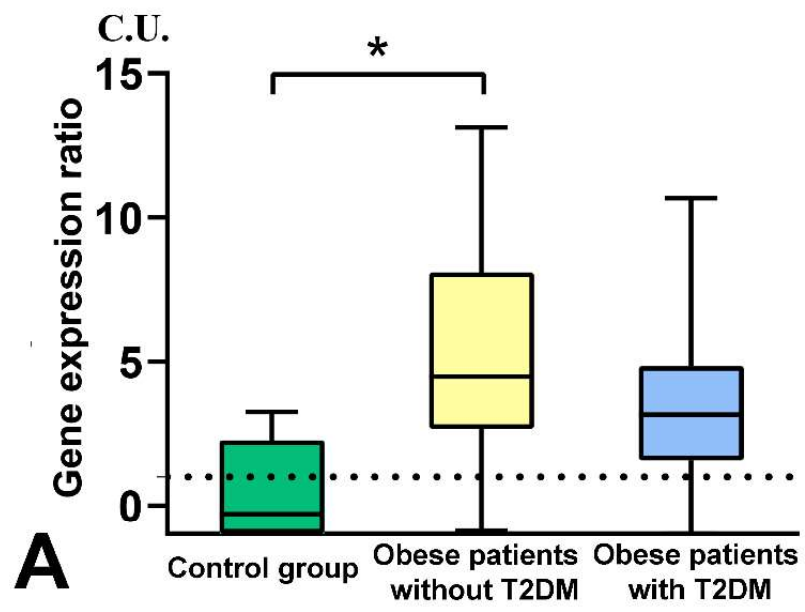

GO
C.U.
Mitofusin-2

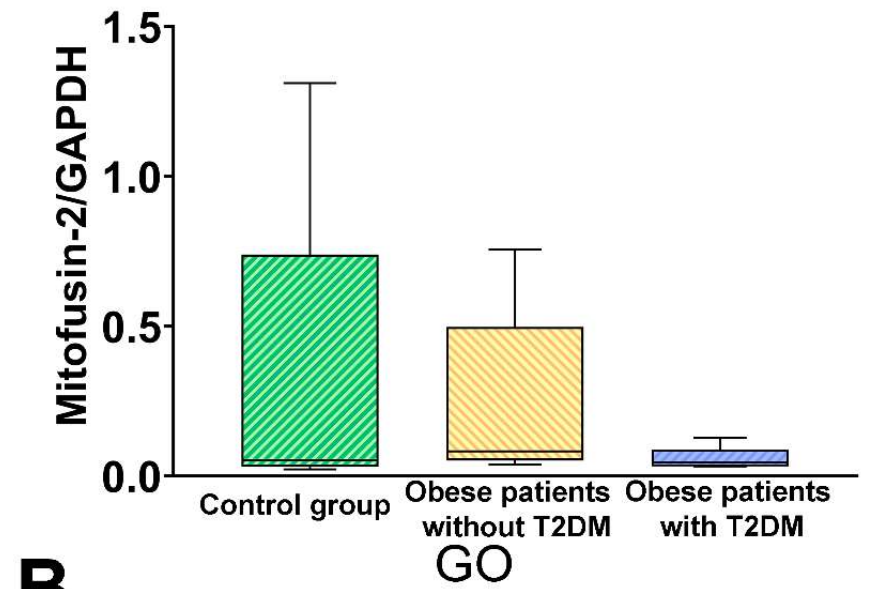

B GO

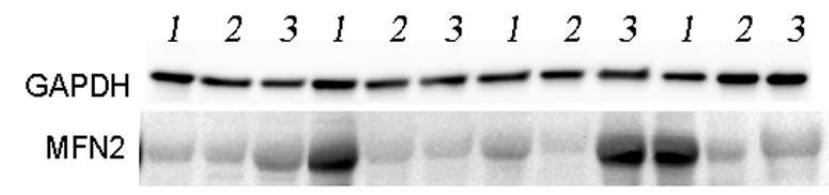

C

GO

\section{MFN2}

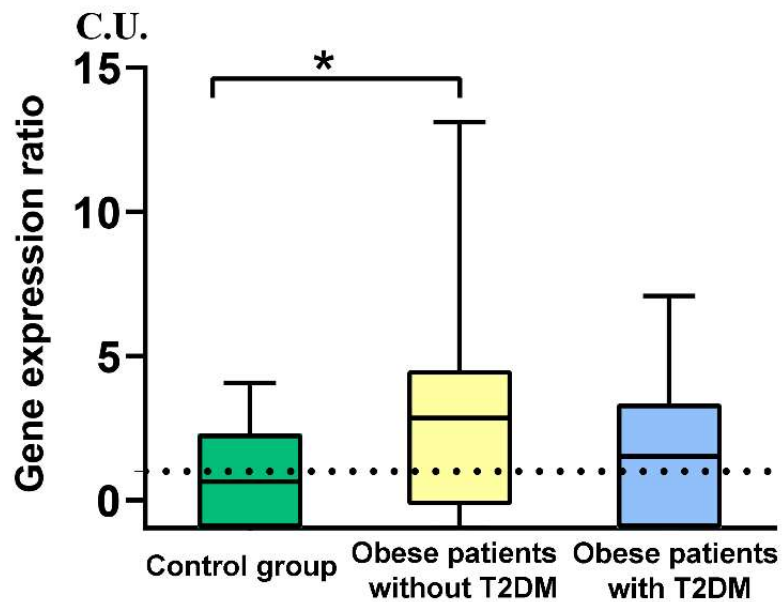

SAT

C.U.

\section{Mitofusin-2}
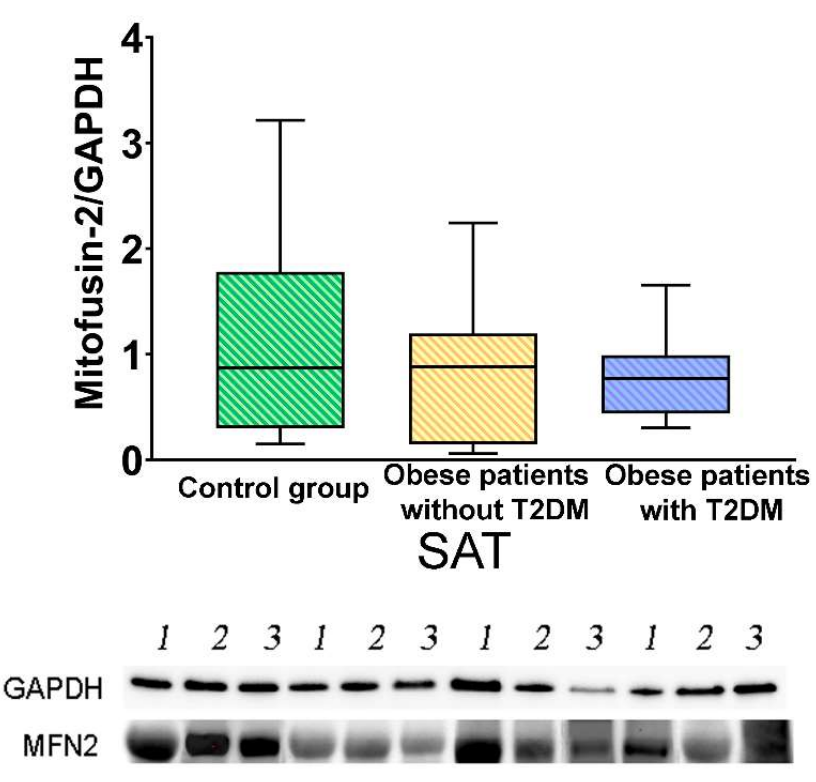

SAT

Figure 7. Study of tissue-specific production of MFN2 in obese patients with and without T2DM. (a) - MFN2 genes expression in GO and SAT; (b) - Mitofusin-2 protein production in GO and SAT, western blot analysis of AT biopsies; (c) - Protein MFN2 Western Blot Bands. ${ }^{*}$ - $\mathrm{p}<0.05$ the significance is determined using the Mann-Whitney criterion for two independent samples. 
TFAM

C.U.
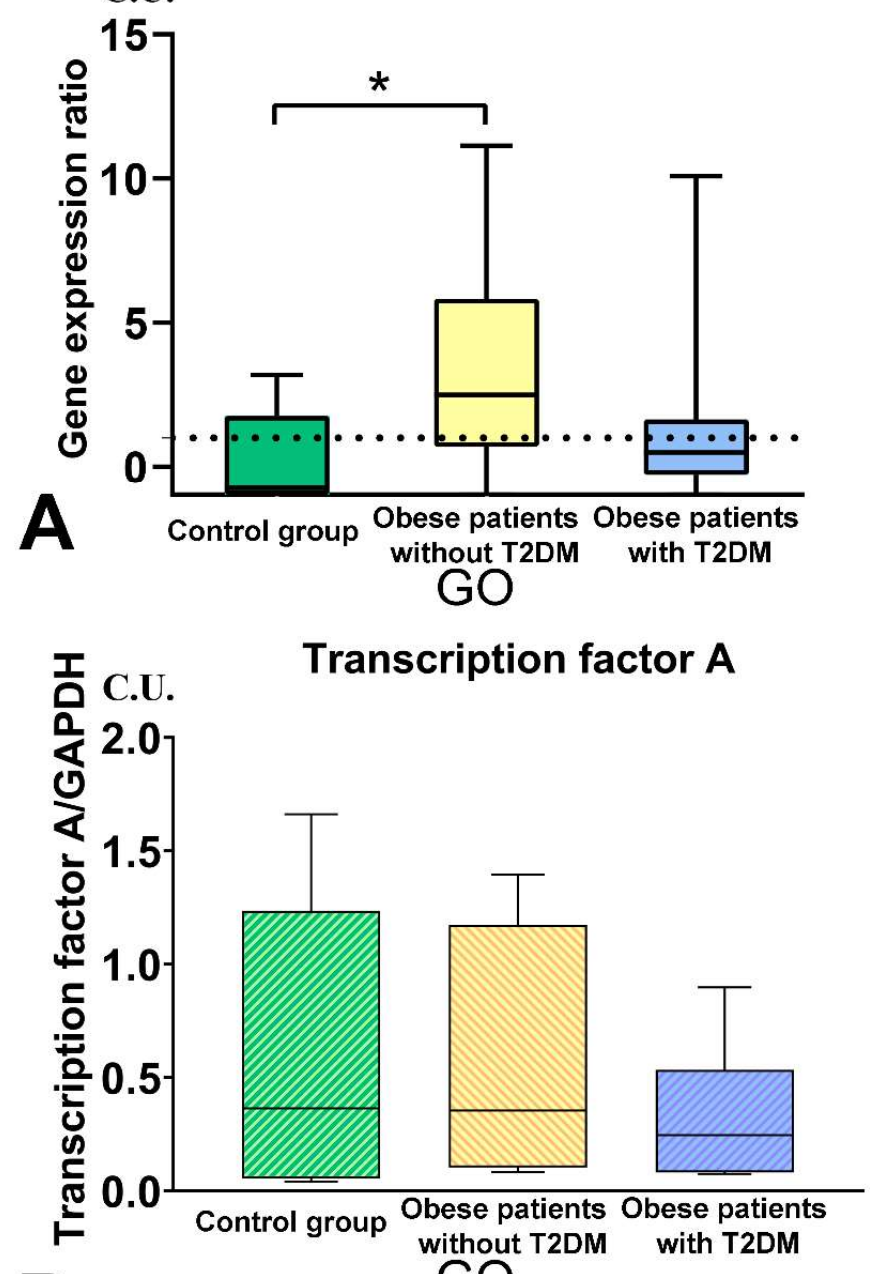

B $\mathrm{GO}$
TFAM
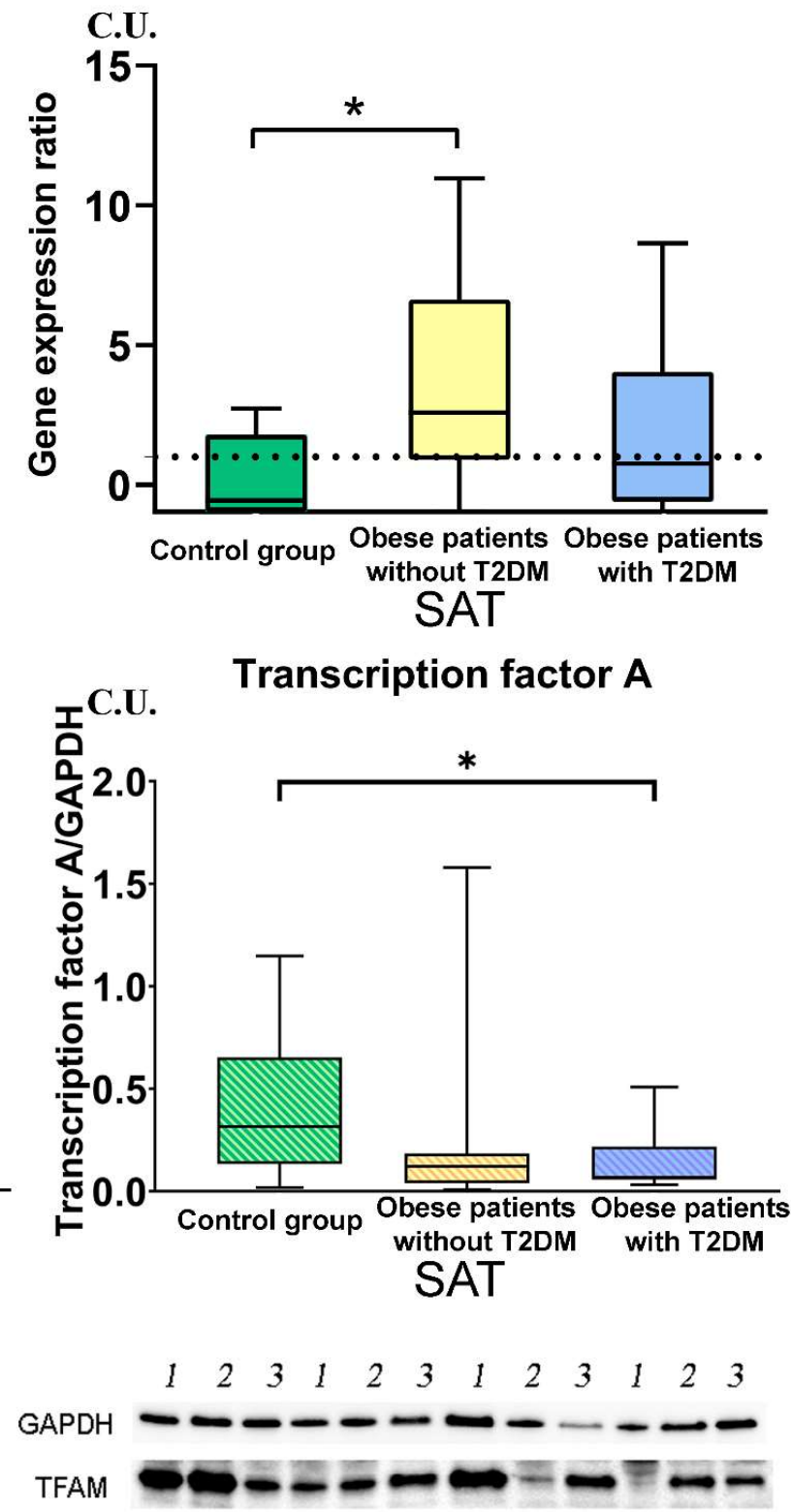

SAT

Figure 8. Study of tissue-specific production of TFAM in obese patients with and without T2DM. (a) - TFAM genes expression in GO and SAT; (b) - Transcription factor A protein production in GO and SAT, western blot analysis of AT biopsies; (c) - Protein TFAM Western Blot Bands. * ${ }^{*}<0.05$ the significance is determined using the Mann-Whitney criterion for two independent samples. 


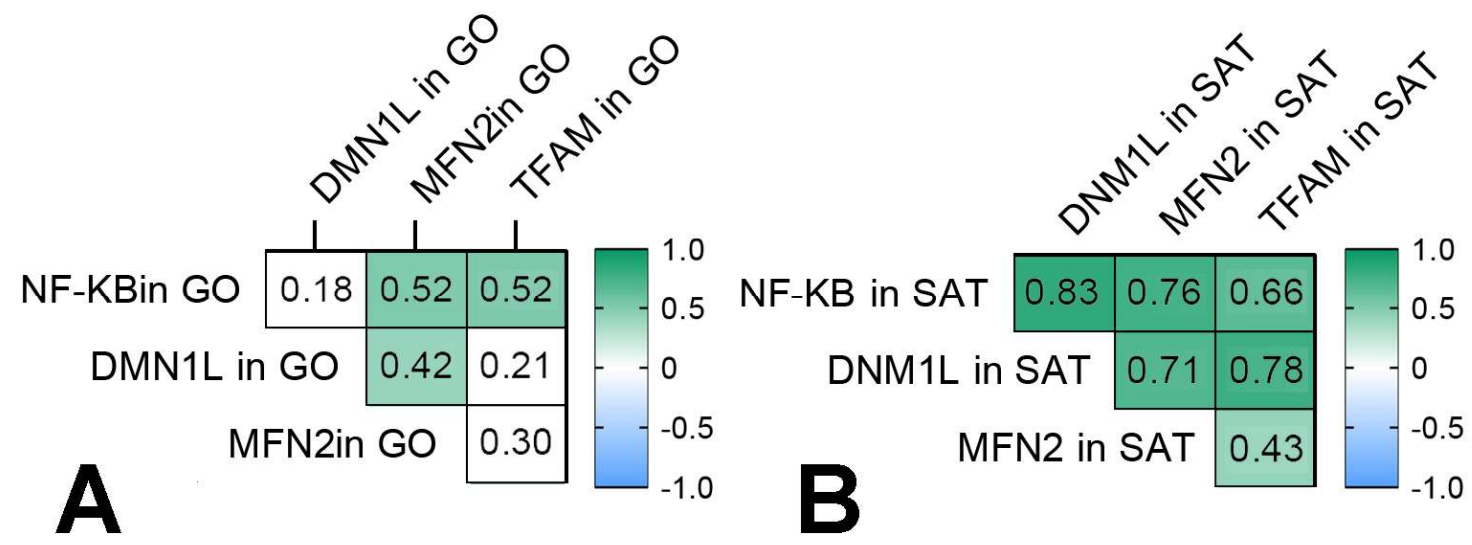

Figure 9. Correlation relationships of NF- $k B 1$, DNM1L, MFN2, and TFAM gene expression in GO and SAT. Filled squares show significant $\mathrm{p}<0.05$.

3.5. TNF receptors and ligands levels have been associated with components of mitochondrial dynamics

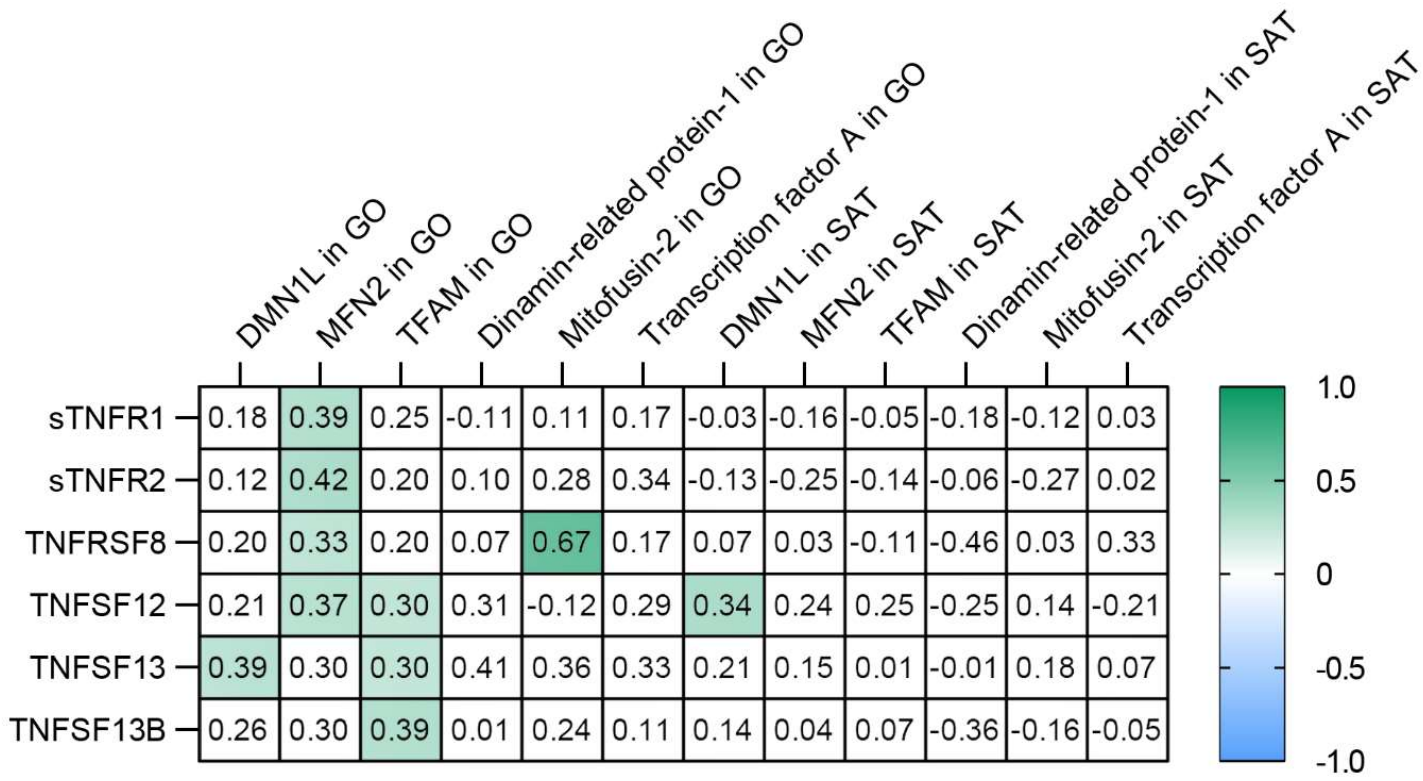

Figure 10. Correlation relationships of sTNF-R1, sTNF-R2, sTNFRSF8, and ligands - TNFSF12, TNFSF13, TNFSF13B with mitochondrial dynamics in all obese patients. Filled squares show significant $p<0.05$.

It was found that sTNF-R1, sTNF-R2, sTNFRSF8, and TNFSF12 levels positively correlated with MFN2 gene expression in GO. TNFSF12, TNFSF13, and TNFSF13B levels were positively correlated with TFAM in GO. TNFSF13 level was positively correlated with DNM1L gene expression in GO. 
Figure 11. Regression Linear Analysis for TNF Receptors and Ligands with the DNM1L, MFN2, and TFAM gene expression in GO and SAT
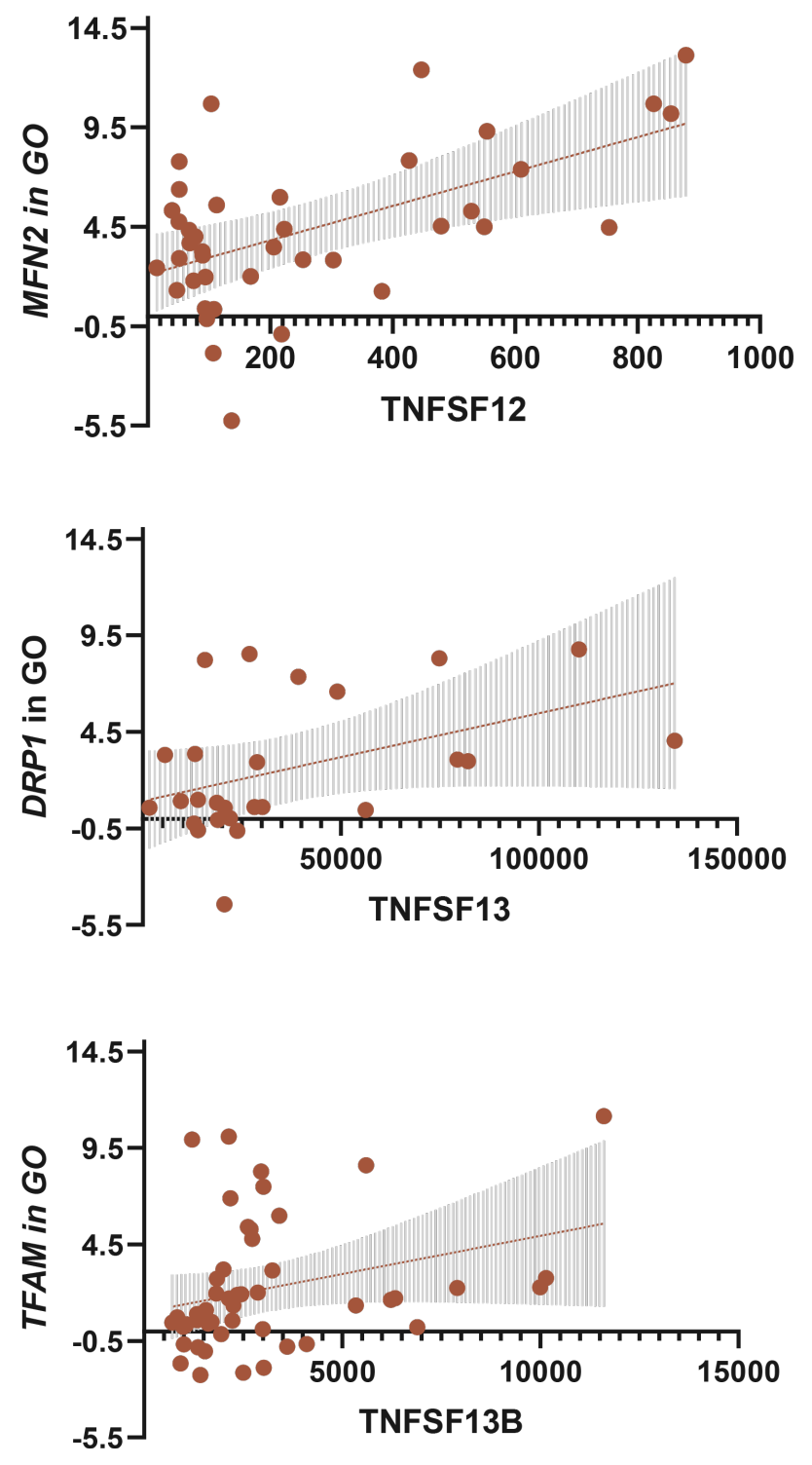

We checked if the multiple regression model included DNM1L, MFN2, and TFAM gene expression in GO and SAT. By sequential fitting, it was found that only the TNFSF12 dependent multiple regression model was statistically significant. Moreover, with the conditional parameter MFN2 gene expression, the regression coefficient and significance increased (Table 4). 
Table 4. Models of multiple regression analysis of the relationship between the sTNF-R1. TNFSF12 and TNFSF12 levels and glucose level, IL10 level, BMI, DNM1L gene expression in GO, MFN2 gene expression in GO, and TFAM gene expression in GO.

\begin{tabular}{l|c|c|c|c|c|c}
\hline \multicolumn{1}{c|}{ Multiple regression } & $\begin{array}{c}\text { Dependent } \\
\text { variable }\end{array}$ & $\begin{array}{c}\text { Independent } \\
\text { variable }\end{array}$ & $\beta$ & $\begin{array}{c}\text { Standard } \\
\text { error }\end{array}$ & $\mathrm{t}$ value & $\mathrm{p}$-value \\
\hline $\begin{array}{l}\text { Multiple regression linear } \\
\text { Model 4 }\end{array}$ & & BMI & -0.217 & 0.087 & -2.493 & $0.0186^{*}$ \\
\cline { 3 - 8 } $\begin{array}{c}\text { Multiple R-squared }=0.626 \\
\text { Adjusted R-squared =0.574 } \\
\text { p-value = 6.419e-06 }\end{array}$ & TNFSF12 & Glucose & -0.208 & 0.094 & -2.204 & $0.0356^{*}$ \\
\cline { 3 - 8 } & & IL10 & 0.334 & 0.149 & 2.246 & $0.0324^{*}$ \\
\cline { 3 - 8 } & & MFN2 in GO & 0.359 & 0.103 & 3.478 & $0.0016^{*}$ \\
\hline
\end{tabular}

Significant $\overline{\mathrm{p}<0.05 \text {. }}$

Thus, we have shown a relationship between sTNF-R1, sTNF-R2, sTNFRSF8, TNFSF12, TNFSF13, TNFSF13B, and mitochondrial dynamics in obese patients. The most significant contribution was made by the TNFSF12 level and contributed to an increase in MFN2 gene expression in GO, an increase in IL-10 levels, a decrease in glucose levels, and a decrease in BMI in obese patients.

\subsection{TNF-a level have been associated with MFN2 gene expression in GO}

The multiple regression model, it was shown that an increase in TNF-a levels influenced a decrease in IL10 levels and MFN2 gene expression in GO.

Table 5. Models of multiple regression analysis of the relationship between the TNF-a levels and Il-10 level and MFN2 gene expression in GO

\begin{tabular}{c|c|c|c|c|c|c}
\hline Multiple regression & $\begin{array}{c}\text { Dependent } \\
\text { variable }\end{array}$ & $\begin{array}{c}\text { Independent } \\
\text { variable }\end{array}$ & $\beta$ & $\begin{array}{c}\text { Standard } \\
\text { error }\end{array}$ & $\mathrm{t}$ value & $\mathrm{p}$-value \\
\hline $\begin{array}{c}\text { Multiple regression linear } \\
\text { Model 5 }\end{array}$ & & IL10 & -0.576 & 0.239 & -2.404 & $0.0286^{*}$ \\
\cline { 3 - 7 } $\begin{array}{c}\text { Multiple R-squared }=0.702, \\
\text { Adjusted R-squared }=0.665, \\
\mathrm{p} \text {-value }=6.123 \mathrm{e}-05\end{array}$ & TNF-a & MFN2 in GO & -0.526 & 0.112 & -4.695 & $0.0001^{*}$ \\
\hline $\begin{array}{l}\mathrm{p}<0.05 . \\
\text { Significant }\end{array}$ & & & & & & \\
\hline
\end{tabular}

\section{Discussion}

This study examined the role of TNF receptors and ligands in the plasma of obese patients depending on the presence/absence of T2DM. Lipid metabolism disorders and high glucose levels were detected in obese patients with T2DM. In obese patients without T2DM, the levels of glucose, cholesterol, high-density lipoproteins (HDL), low-density lipoproteins (LDL), and triglycerides were predominantly inside the reference values (World Health Organization (1999-2013)).

Increased levels of receptors sTNF-R1, sTNF-R2, sCD30/TNFRSF8, and ligands TVVEAK/TNFSF12, APRIL/TNFSF13, BAFF/TNFSF13B are characteristic of obese patients without T2DM. The TNF-mediated inflammatory response may suppress by sTNFR1 and sTNFR2 in blood plasma [16]. This fact indicates compensatory mechanisms associated with the action of TNF receptors and ligands in obese patients without T2DM. Receptors interacting with members of the TNF family type 2 and type 3 may have protective effects against metabolic complications [1]. Correlation and regression analysis TNFSF12 and TNFSF13B levels showed that increased levels were associated with decreased BMI, a reduction of glucose levels, and an increased in IL10 (Figure 4, Suppl. 1). 
A high concentration of sTNF-R1, TNFSF12, TNFSF13, TNFSF13B contributes to maintaining normal lipid metabolism in obese patients $(\mathrm{p}<0.05)$. A decrease in HDL and an increase in LDL are associated with obesity. Plasma levels of sTNF-R1, TNFSF12, TNFSF13, TNFSF13B positively correlated with HDL levels and negatively correlated with LDL levels [17].

A positive correlation was found between the content of sTNF-R1, sTNF-R2, sTNFRSF8, TNFSF12, TNFSF13, TNFSF13B in blood plasma with the level of antiinflammatory cytokine IL-10 and negative with TNF. IL-10, known as a factor inhibiting cytokine synthesis, is considered a key immunoregulatory cytokine. IL-10 is synthesized compensatory in response to the action of TNF and other proinflammatory cytokines and can inhibit inflammation under various pathophysiological conditions [18]. The data indicate the anti-inflammatory role of high concentrations of sTNF-R1, sTNF-R2, sTNFRSF8, TNFSF13, TNFSF13B in obesity.

STNF-R1, sTNF-R2, sTNFRSF8, TNFSF12, TNFSF13, TNFSF13B levels decreased with increasing $\mathrm{BMI}$ in obese patients. This fact may indicate a depletion of the compensatory potential in obesity.

Thus, an increase sTNFRSF8 and TNFSF13 is associated with an increase in the production of IL-10, HDL, and a decrease in BMI, LDL, TNF in plasma obese patients. In addition, an increase in plasma levels of sTNFRSF8, TNFSF12, TNFSF13 was associated with a decrease in serum glucose concentration in obese patients. Shown a protective role of elevated levels of sTNF-R1, sTNF-R2, sTNFRSF8, TNFSF12, TNFSF13, TNFSF13B in relation to the development of T2DM obese patients $(p<0.05)$. We showed by regression multivariate analysis that an increase in TNFSF12 and TNFSF13B levels affects a decrease in blood glucose concentration, a reduction in BMI, and increased IL10 levels in blood plasma. We showed by regression multivariate analysis that an increase in sTNF-R1 levels affects a decrease in blood glucose concentration, a reduction in BMI.

VAT is the most metabolically active fat depot [19]. It is assumed that metabolic complications are associated with metabolic disorders in the GO [19]. The NF-kB1 gene expression in the GO increased in obese patients with and without T2DM compared with the control group.

SAT is considered a protective fat depot [20]. There is an opinion that is in SAT that pro-inflammatory cytokines and adipokines are produced [20]. The NF- $k B 1$ gene expression in the SAT increased in obese patients without T2DM compared with the control group and obese patients with T2DM.

High level of NF-kB1 gene expression unexpected for obese patients without metabolic complications. The role of NF-kB needs to be investigated in more detail to understand why NF-kB1 gene expression is increased in obese patients without T2DM in the visceral and subcutaneous adipose tissues and NF-kB1 gene expression is not so significant in patients with T2DM.

The canonical NF- $\kappa \mathrm{B}$ pathway is activated mainly due to proinflammatory receptors and genotoxic agents $[7 ; 8]$. The canonical pathway activates the inhibitor of NF- $\kappa \mathrm{B}$ kinase (IKK) complex, consisting of the catalytic kinases IKK $\alpha$ and IKK $\beta$ and the regulatory subunit IKK- $\gamma$ (NEMO) [8]. In this case, the p105 subunit (NFKB1 gene product) is processed into p50. P50 is associated with $\mathrm{I} \kappa \mathrm{B}$ and remains an inactive heterodimer called RelA (p65 subunit) (or c-Rel) [8]. Further, IKK phosphorylates $\mathrm{I} \kappa \mathrm{B} \alpha$ and ubiquitination of $\mathrm{I} \kappa \mathrm{B} \alpha$ occurs [8]. I $\kappa \mathrm{B} \alpha$ is cleaved and releases the p50/RelA heterodimer, allowing gene transcription to be activated [8].

Activation of the non-canonical pathway begins with the stabilization of NF- $\kappa B$ inducing kinase (NIK). NIK phospholyrates and activates IKK $\alpha$. The homodimeric IKK $\alpha$ complex phosphorylates and triggers p100 processing. Further, the p100 subunit is processed to p52, which is a distinctive feature of this pathway. Interestingly, untreated p100 inhibits DNA binding and nuclear localization of the NF- $\kappa B$ heterodimer [8]. p52 and its hetero- or homodimeric partner are released to bind to DNA in the nucleus and affect transcription $[7,8]$. 
The non-canonical activation of NF- $\kappa \mathrm{B}$ is stimulated by family members of specific TNF receptors belonging to the second and third classes [8]. The TNFSF12, TNFSF13, and TNFSF13B levels were correlated with NF- $k B 1$ gene expression in GO (Suppl 2).

We noticed that $N F-k B 1$ gene expression positively correlated with the components of mitochondrial dynamics in GO and SAT (Figure 9). NF-kB can trigger genes not only for cell death but also genes that contribute to the survival of oxidative stress [8]. Recent studies have documented the importance of mitochondrial dynamics in the pathogenesis of T2DM [11, 21-23]. This study shows that obese patients without T2DM increased mitochondrial fission, fusion, and mitochondrial transcription: DNM1L, MFN2, and TFAM gene expression in GO and SAT was higher than in the control group. Judging by the change in DNM1L and MFN2 gene expression levels, mitochondrial division and fusion are in balance in obese patients without T2DM.

The fusion of mitochondria restores their function [26,27]. Increased MFN2 gene expression in GO and SAT may be a protective mechanism for maintaining normal mitochondrial dynamics in adipose tissue in obese patients without T2DM. We used multiple regression models and tested models of the effect of TNF receptors and ligands on MFN2 gene expression in GO and SAT. The TNFSF12 affects the dependent variables - MFN2 gene expression in GO, glucose level, IL10 level, and BMI $\left(r^{2}=0.62, p<0.05\right)$. Moreover, this model of multiple regression was the strongest among all studied (Table 4). We hypothesize that TNFSF12 is involved in maintaining mitochondrial fusion in GO in obese patients without T2DM. Plasma TNFSF12 levels contribute to the maintenance of normal carbohydrate metabolism in obese patients without T2DM.

Fission processes are associated with the degradation of mitochondria and, therefore, are induced under conditions of mitochondrial damage [24,25]. Balancing mitochondrial dynamics is very important for metabolic health [11]. The predominance of this or that process has a pathological significance [21]. The biological meaning of an increase in mitochondrial fission is not completely clear. It has been reported that high glucose levels can activate mitochondrial fission 1 protein (FIS1), which leads to increased fragmentation of mitochondria and overproduction of ROS [21]. The DRP1 protein production in SAT increased in obese patients with T2DM relative to the control group. The TNFSF13 was associated with mitochondrial fission - correlation and regression analyses showed an association of TNFSF13 level with DNM1L gene expression in GO. However, TNFSF13 was not included in the multiple regression models. We assume that TNFSF13 independently affects DNM1L gene expression, and this relationship requires further study.

In obese patients with T2DM, under oxidative stress conditions and increased ROS production, mitochondrial functioning is impaired [11]. The TFAM gene plays an essential role in mitochondrial biogenesis and cell physiology, maintains replication and transcription of mtDNA and regulates the mtDNA copy number [24]. TFAM protein production decreased in SAT in obese patients with T2DM compared to the control group. Our previous work has provided compelling evidence for the effect of high levels of TNF on high levels of mtDNA copy number in adipose tissue. Moreover, In patients with morbid obesity (BMI $>40 \mathrm{~kg} / \mathrm{m} 2)$, the mtDNA copy number was reduced in adipose tissue relative to patients with I and II degrees of obesity [26,27]. Therefore, the TFAM gene expression increase may indicate an increase in the mtDNA transcription [24]. High TFAM gene expression in muscle reduces fat mass, increases energy expenditure, and reduces oxidative stress [23]. It is suggested that TFAM activation may be a therapeutic strategy for treating peripheral neuropathy [22]. In obese patients without T2DM, the TFAM gene expression in GO increased relative to the control group. In obese patients, correlation and regression analysis showed a relationship between the TNFSF13B and TFAM gene expression in GO.

The influence of TNF receptors and ligands on protection against metabolic complications in obesity, particularly T2DM, is also due to the blocking of the effects of TNF-a. TNF-a levels negatively correlated with soluble forms of TNF receptors and 
ligands. Thus, in a multiple regression model, it was shown that an increase in TNF-a levels influenced a decrease in IL10 levels and MFN2 gene expression in GO.

Analyzing the action of TNF receptors and ligands with systemic effects on interdependent mechanisms regulating cascades of signaling intracellular pathways can expand the fundamental understanding of the components of the signaling network and take a new knowledge at the pathogenetic mechanisms of diseases.

\section{Conclusions}

1. Increased levels of receptors sTNF-R1, sTNF-R2, TNFRSF8 and ligands TNFSF12, TNFSF13, TNFSF13B are signs of obese patients without T2DM.

2. Increases in TNFSF12, TNFSF13B, and sTNF-R1 levels are associated with decreased glucose concentration and decreased BMI in obese patients.

3. The TNFSF12 and TNFSF13B levels were associated with the NFkB1 gene expression in GO in obese patients.

4. The NFkB1 gene expression increased in GO and SAT in obese patients without T2DM compared with the control group, and NFkB1 gene expression was associated with components of mitochondrial dynamic - DNM1L, MFN2, and TFAM gene expression.

5. The DNM1L, MFN2, and TFAM gene expression levels responsible for regulating mitochondrial dynamics were increased in obese patients without T2DM and were unbalanced in patients with obesity and T2DM.

6. The TNFSF12 contributed to a decrease in glucose levels, a decrease in BMI, and an increase in IL-10 levels by influencing the gene expression of MFN2 in GO, which supports mitochondrial fusion.

Supplementary Materials: Figure S1: Regression Linear Analysis for TNF Receptors and Ligands, Figure S2: Correlation relationship between all investigated parameters.

Author Contributions: Conceptualization, D.S.; methodology, A.K., H.Q., A.D., D.M. and P.Z.; software, E.S.; validation, L.L. and M.V.; formal analysis, A.K. and E.K.; data curation, D.S.; writing - original draft preparation, D.S.; writing - review and editing, D.S and M.V..; visualization, E.S.; funding acquisition, L,L, and D.S. All authors have read and agreed to the published version of the manuscript

Funding: The study was supported by a grant from the Russian Science Foundation (project no. 2075-00079 (western blot analysis of mitochondrial dynamics)); by the Russian Foundation for Basic Research and Kaliningrad Region (No. 19-415-393004-r_mol_a and No. 19-44-390005-r_a (biochemical analysis, analysis of inflammation)), the state assignment (No. FZWM-2020-0010), and the state support of leading scientific schools of the Russian Federation (No. 2495.2020.7).

Institutional Review Board Statement: The study was conducted according to the guidelines of the Declaration of Helsinki, and approved by the Institutional Review Board (or Ethics Committee) of IKBFU (protocol code 2 and 29.11.2018).

Informed Consent Statement: Informed consent was obtained from all subjects involved in the study. Written informed consent has been obtained from the patients to publish this paper

Data Availability Statement: The data are available upon request from the author's correspondents.

Acknowledgments: We would like to express our gratitude to Dr. Natalya Todosenko (Immanuel Kant Baltic Federal University) for help in the method of bio plex analysis of cytokines in plasma samples and to Dr. Natalia Gazatova (Immanuel Kant Baltic Federal University) for biochemical analysis

Conflicts of Interest: The authors declare no conflict of interest.

\section{References}

1. Sonar, S.; Lal, G. Role of Tumor Necrosis Factor Superfamily in Neuroinflammation and Autoimmunity. Front. Immunol. 2015, 6, doi:10.3389/fimmu.2015.00364. 
2. Niewczas, M.A.; Gohda, T.; Skupien, J.; Smiles, A.M.; Walker, W.H.; Rosetti, F.; Cullere, X.; Eckfeldt, J.H.; Doria, A.; Mayadas, T.N.; et al. Circulating TNF Receptors 1 and 2 Predict ESRD in Type 2 Diabetes. J. Am. Soc. Nephrol. JASN 2012, 23, 507-515, doi:10.1681/ASN.2011060627.

3. Rinaldi, I. The Role of Reed-Sternberg CD30 Receptor and Lymphocytes in Pathogenesis of Disease and Its Implication for Treatment. Acta Medica Indones. 2018, 50, 93-95.

4. Acharya, A.B.; Chandrashekar, A.; Acharya, S.; Shettar, L.; Thakur, S. Serum STWEAK Levels in Chronic Periodontitis and Type 2 Diabetes Mellitus. Diabetes Metab. Syndr. 2019, 13, 1609-1613, doi:10.1016/j.dsx.2019.03.027.

5. Croft, M.; Duan, W.; Choi, H.; Eun, S.-Y.; Madireddi, S.; Mehta, A. TNF Superfamily in Inflammatory Disease: Translating Basic Insights. Trends Immunol. 2012, 33, 144-152, doi:10.1016/j.it.2011.10.004.

6. Zhang, Y.; Kent, J.W.; Olivier, M.; Ali, O.; Broeckel, U.; Abdou, R.M.; Dyer, T.D.; Comuzzie, A.; Curran, J.E.; Carless, M.A.; et al. QTL-Based Association Analyses Reveal Novel Genes Influencing Pleiotropy of Metabolic Syndrome (MetS). Obesity 2013, 21, 2099-2111, doi:https://doi.org/10.1002/oby.20324.

7. Suryavanshi, S.V.; Kulkarni, Y.A. NF-K $\beta$ : A Potential Target in the Management of Vascular Complications of Diabetes. Front. Pharmacol. 2017, 8, doi:10.3389/fphar.2017.00798.

8. Morgan, M.J.; Liu, Z. Crosstalk of Reactive Oxygen Species and NF-KB Signaling. Cell Res. 2011, 21, 103-115, doi:10.1038/cr.2010.178.

9. Lee, J.H.; Park, A.; Oh, K.-J.; Lee, S.C.; Kim, W.K.; Bae, K.-H. The Role of Adipose Tissue Mitochondria: Regulation of Mitochondrial Function for the Treatment of Metabolic Diseases. Int. J. Mol. Sci. 2019, 20, doi:10.3390/ijms20194924.

10. Heinonen, S.; Buzkova, J.; Muniandy, M.; Kaksonen, R.; Ollikainen, M.; Ismail, K.; Hakkarainen, A.; Lundbom, J.; Lundbom, N.; Vuolteenaho, K.; et al. Impaired Mitochondrial Biogenesis in Adipose Tissue in Acquired Obesity. Diabetes 2015, 64, 3135-3145, doi:10.2337/db14-1937.

11. Sivitz, W.I.; Yorek, M.A. Mitochondrial Dysfunction in Diabetes: From Molecular Mechanisms to Functional Significance and Therapeutic Opportunities. Antioxid. Redox Signal. 2010, 12,537-577, doi:10.1089/ars.2009.2531.

12. Shi, J.-H.; Sun, S.-C. Tumor Necrosis Factor Receptor-Associated Factor Regulation of Nuclear Factor KB and Mitogen-Activated Protein Kinase Pathways. Front.Immunol. 2018, 9, 1849, doi:10.3389/fimmu.2018.01849.

13. Hayden, M.S.; Ghosh, S. Regulation of NF-KB by TNF Family Cytokines. Semin. Immunol. 2014, 26, 253-266, doi:10.1016/j.smim.2014.05.004.

14. Bassols, J.; Moreno, J.M.; Ortega, F.; Ricart, W.; Fernandez-Real, J.M. Characterization of Herpes Virus Entry Mediator as a Factor Linked to Obesity. Obes. Silver Spring Md 2010, 18,239-246, doi:10.1038/oby.2009.250.

15. Livak, K.J.; Schmittgen, T.D. Analysis of relative gene expression data using real-time quantitative PCR and the 2(-Delta Delta C(T)) Method. Methods. 2001, vol.25, 4,402-408. doi: 10.1006/meth.2001.1262.

16. So, T.; Ishii, N. The TNF-TNFR Family of Co-Signal Molecules. Adv. Exp. Med. Biol. 2019, 1189, 53-84, doi:10.1007/978-981-329717-3_3.

17. Bora, K.; Pathak, M.S.; Borah, P.; Das, D. Association of Decreased High-Density Lipoprotein Cholesterol (HDL-C) With Obesity and Risk Estimates for Decreased HDL-C Attributable to Obesity. J.Prim. Care Community Health 2017, 8, 26-30, doi:10.1177/2150131916664706.

18. Mühl, H. Pro-Inflammatory Signaling by IL-10 and IL-22: Bad Habit Stirred Up by Interferons? Front. Immunol. 2013, 4, doi:10.3389/fimmu.2013.00018.

19. Ndisang, J.F.; Vannacci, A.; Rastogi, S. Insulin Resistance, Type 1 and Type 2 Diabetes, and Related Complications 2017.J.Diabetes Res. 2017, 2017, doi:10.1155/2017/1478294.

20. Tiller, G.; Laumen, H.; Fischer-Posovszky, P.; Finck, A.; Skurk, T.; Keuper, M.; Brinkmann, U.; Wabitsch, M.; Link, D.; Hauner, H. LIGHT (TNFSF14) Inhibits Adipose Differentiation without Affecting Adipocyte Metabolism. Int. J. Obes. 2011, 35, 208-216, doi:10.1038/ijo.2010.126.

21. Yu, T.; Robotham, J.L.; Yoon, Y. Increased Production of Reactive Oxygen Species in Hyperglycemic Conditions Requires Dynamic Change of Mitochondrial Morphology. Proc. Natl. Acad. Sci. U. S. A. 2006, 103,2653-2658, doi:10.1073/pnas.0511154103.

22. Chandrasekaran, K.; Anjaneyulu, M.; Inoue, T.; Choi, J.; Sagi, A.R.; Chen, C.; Ide, T.; Russell, J.W. Mitochondrial Transcription Factor A Regulation of Mitochondrial Degeneration in Experimental Diabetic Neuropathy. Am. J. Physiol. Endocrinol. Metab. 2015, 309,E132-141, doi:10.1152/ajpendo.00620.2014.

23. Koh, J.-H.; Johnson, M.L.; Dasari, S.; LeBrasseur, N.K.; Vuckovic, I.; Henderson, G.C.; Cooper, S.A.; Manjunatha, S.; Ruegsegger, G.N.; Shulman, G.I.; et al. TFAM Enhances Fat Oxidation and Attenuates High-Fat Diet-Induced Insulin Resistance in Skeletal Muscle. Diabetes 2019, 68, 1552-1564, doi:10.2337/db19-0088.

24. 1. El-Hattab, A.W.; Craigen, W.J.; Scaglia, F. Mitochondrial DNA Maintenance Defects. Biochim. Biophys. Acta Mol. Basis Dis. 2017, 1863, 1539-1555, doi:10.1016/j.bbadis.2017.02.017.

25. Luan, G.; Li, G.; Ma, X.; Jin, Y.; Hu, N.; Li, J.; Wang, Z.; Wang, H. Dexamethasone-Induced Mitochondrial Dysfunction and Insulin Resistance-Study in 3T3-L1 Adipocytes and Mitochondria Isolated from Mouse Liver. Molecules 2019, 24, doi:10.3390/molecules24101982.

26. Litvinova, L.; Zatolokin, P.; Vulf, M.; Mazunin, I.; Skuratovskaia, D. The Relationship between the MtDNA Copy Number in Insulin-Dependent Tissues and Markers of Endothelial Dysfunction and Inflammation in Obese Patients. BMC Med. Genomics 2019, 12, 41, doi:10.1186/s12920-019-0486-7. 
27. Skuratovskaia, D.; Zatolokin, P.; Vulf, M.; Mazunin, I.; Litvinova, L. Interrelation of Chemerin and TNF- $\alpha$ with MtDNA Copy Number in Adipose Tissues and Blood Cells in Obese Patients with and without Type 2 Diabetes. BMC Med. Genomics 2019, 12, 40, doi:10.1186/s12920-019-0485-8.

Supplementary Materials:

Figure S1: Regression Linear Analysis for TNF Receptors and Ligands 

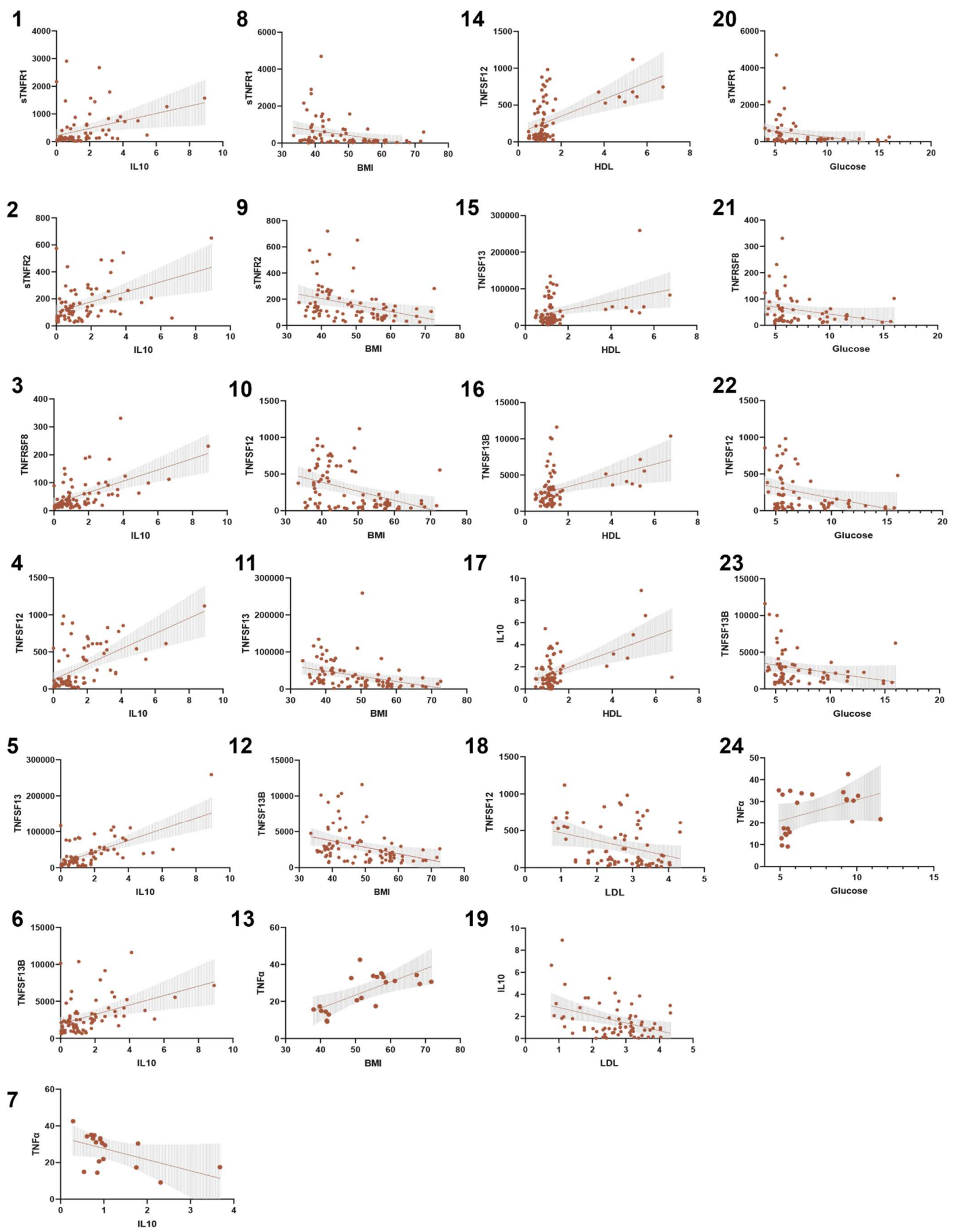

Figure S2: Correlation relationship between all investigated parameters. 


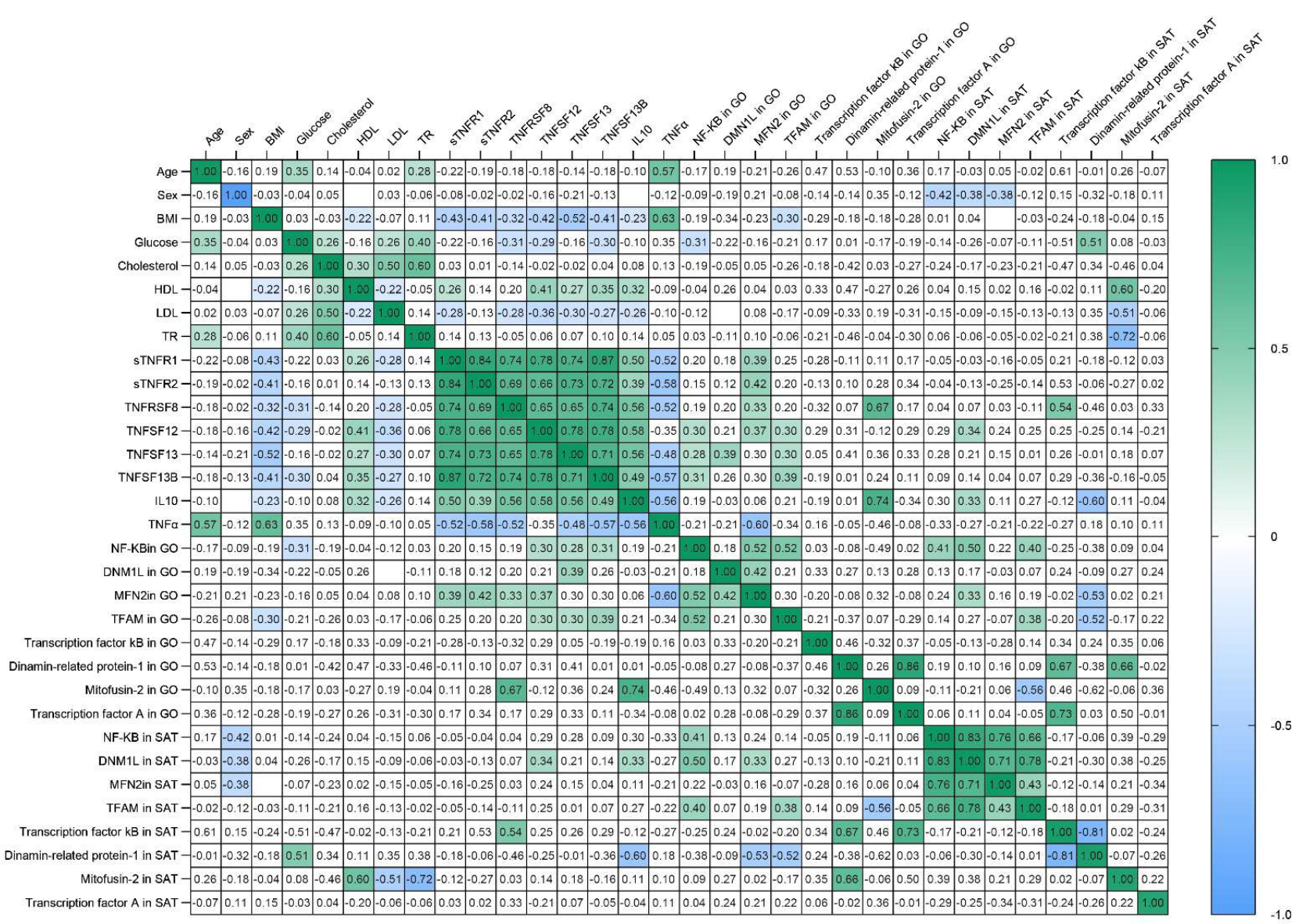

